\title{
MEASURING WELFARE IN RESTRUCTURED ELECTRICITY MARKETS
}

\author{
Erin T. Mansur*
}

Abstract-Restructuring electricity markets has enabled wholesalers to exercise market power. Using a common method to measure competition, several studies have found substantial inefficiencies. This method overstates actual welfare loss by ignoring production constraints that result in non-convex costs. I develop an alternative method that accounts for these constraints and apply it to the Pennsylvania, New Jersey, and Maryland market. For the summer following restructuring, the common method implies that market imperfections resulted in considerable welfare loss, with actual production costs exceeding the competitive model's estimates by $13 \%-21 \%$. In contrast, my method finds that actual costs were only between $3 \%$ and $8 \%$ above the competitive levels.

\section{Introduction}

$\mathrm{R}$ ESTRUCTURING electricity markets has enabled wholesalers to exercise market power. Using a common method of measuring competitive behavior in these markets, several studies have found substantial inefficiencies. ${ }^{1}$ This paper argues that this method overstates actual welfare loss. I develop an alternative method that accounts for firms' production constraints that result in cost nonconvexities. The paper then applies the method to the Pennsylvania, New Jersey, and Maryland (PJM) wholesale electricity market.

In general, welfare loss may occur because of allocative and production inefficiencies. However, wholesale electricity markets do not have allocative inefficiencies, in the short run, because derived demand is nearly completely inelastic. There are two reasons for this. First, consumers have no incentive to reduce quantity demanded at higher wholesale prices because the regulatory structure of electricity retail markets has kept consumers' rates constant. ${ }^{2}$ Second, the firms that procure customers' electricity in the wholesale market are mandated to provide the power at any cost.

Therefore, the only short-run welfare effects in electricity markets result from inefficient production. Strategic firms with asymmetric costs, or firms with asymmetric strategies, distort production decisions from the competitive equilibrium (Borenstein \& Farrell, 2000). This causes cross-firm production inefficiencies. Individually, a firm will achieve a

Received for publication September 7, 2004. Revision accepted for publication February 21, 2007.

* Associate Professor, Yale School of Management.

I thank Severin Borenstein, Jim Bushnell, Judy Chevalier, Bill Hogan, Jun Ishii, Ed Kahn, Nat Keohane, Aviv Nevo, Sharon Oster, Ben Polak, Steve Puller, Fiona Scott Morton, Frank Wolak, Catherine Wolfram, the editor, and two anonymous referees for helpful suggestions. The financial support of the California Public Utilities Commission and the University of California Energy Institute is gratefully acknowledged.

${ }^{1}$ This method has been used primarily to measure markups (for example, see Wolfram, 1999; Joskow \& Kahn, 2002; and Mansur, 2007). However, it has also been used to quantify welfare loss (for example, see Borenstein, Bushnell, \& Wolak, 2002).

${ }^{2}$ A few customers have "interruptible" contracts that are exercised when the quantity demanded approaches the capacity of supply, causing customers to curtail the quantity of electricity demanded. As this does not depend on price, demand shifts but remains completely inelastic. given output level by minimizing its own production costs. However, in aggregate, the output level is not produced using the least costly technology. ${ }^{3}$ This paper measures these production distortions.

The standard method, which is referred to as the competitive benchmark analysis, has been developed to simulate wholesale electricity prices that are consistent with a competitive market. ${ }^{4}$ This "static" method ignores production constraints and has primarily been used to measure market transfers. In addition, Borenstein, Bushnell, and Wolak (henceforth BBW, 2002) use this method to quantify welfare loss. In this paper, I predict output decisions for a similar "static" competitive benchmark analysis counterfactual for the PJM market. I then compare the static model's total variable costs with actual variable costs. For the first summer after PJM restructured, in 1999, the actual costs substantially exceeded these static simulations of competitive costs.

However, by ignoring certain types of production constraints, this method overstates production inefficiencies from restructuring. This static technique assumes that power plants operate following an on-off strategy of producing at full capacity if and only if price exceeds (or equals) marginal costs of production. Yet, the process of producing electricity efficiently requires that firms consider several non-convexities in costs. For example, when a firm starts a "generating unit" in order to produce electricity, it incurs start-up costs that typically range between $\$ 100$ and $\$ 7,000 .^{5}$ These costs impose intertemporal constraints on production decisions.

With start-up costs, it may be more efficient to continue operating a generating unit with a relatively high marginal cost than to fire up a unit with lower marginal costs (but which would have to incur start-up costs). This tradeoff between higher marginal costs and start-up costs is of great

\footnotetext{
${ }^{3}$ Furthermore, an individual oligopolist will not necessarily produce less than it would have in a perfectly competitive market. Levin (1985) shows that, in an oligopoly with asymmetric costs, some producers may increase production relative to competitive levels. Note that firms can potentially exercise market power without distorting production; if all firms uniformly increase bids, the optimal order of production will not be distorted.

${ }^{4}$ Wolfram (1999) uses this technique to examine pricing in the England and Wales electricity market. Since then, the technique has been used in studies of many other markets, including California (Borenstein, Bushnell, \& Wolak, 2002; Joskow \& Kahn, 2002); New England (Bushnell \& Saravia, 2002); and PJM (Mansur, 2007). Other studies have made similar assumptions about intertemporal constraints in determining marginal costs. These include Wolfram (1998), Wolak (2000, 2003), Hortaçsu and Puller (forthcoming), Fabra and Toro (2005), and Puller (2007).

${ }^{5}$ Power plants consist of several independently operating "generating units," each composed of a boiler, a generator, and a smokestack. This range represents the 5th and 95th percentile of start-up costs for coal, oil, and natural gas generating units in the eastern U.S. transmission grid using output data from the PROSYM model (Kahn, 2000).
} 
practical importance. With large within-day variation in demand and no economically feasible method of storing electricity, demand is met with a variety of current generation technologies. ${ }^{6}$ This practical reality makes the exercise of this paper particularly relevant.

Harvey and Hogan (2001a, 2001b) and others have noted the ramifications of ignoring production constraints in simulating equilibrium prices. ${ }^{7}$ Electrical engineers have studied this "unit commitment" problem extensively. Using many methods, they solve the cost-minimization problem subject to production constraints and an equilibrium condition. ${ }^{8}$

In contrast to the engineering literature, this paper uses a revealed preferences argument to determine how costminimizing firms behave. I provide an ex post analysis of firms' production behavior assuming that they have solved the unit commitment problem. It is not the intention of this paper to solve the difficult optimization problem in order to construct a counterfactual benchmark. The purpose is to ask whether, by ignoring production constraints, the static method common to the literature is likely to result in substantial biases in measuring welfare. I do this by using a reduced-form representation of firm behavior.

With data from the summer of 1998, prior to restructuring, this paper examines the factors involved in firms' actual production decisions. I model production as a function of prices and costs, allowing the coefficients to differ by generating unit. First, I use these coefficient estimates to predict production levels for the pre-restructuring period. For this period, my "intertemporal" model fits actual production decisions substantially better than the static model. Then, using the coefficient estimates, I extrapolate how firms would have behaved in 1999 had restructuring not occurred.

For the initial summer of restructuring, I compare actual variable costs with estimates of variable costs from my intertemporal model. First, I estimate variable costs using the actual prices. That summer, firms did set prices above those that would have occurred in a competitive market (Mansur, 2007). If post-restructuring prices exceeded those clearing a competitive market, then estimates based on observed prices will overstate production and costs. In turn,

\footnotetext{
${ }^{6}$ The amount of within-day variation in hourly demand can be quite significant. For example, the average coefficient of variation, within a day, in the United States is approximately 0.15 (Holland \& Mansur, forthcoming).

${ }^{7}$ Harvey and Hogan (2001a) note, "It is a straightforward result of unit commitment logic that when [start-up costs, minimum-load costs, and operating parameters such as minimum down times and run times] exist, it will at times be more efficient to meet load with high incremental cost output from a unit that is already on-line or a high-cost but quick-start unit, than to meet that load by starting a unit with low incremental energy costs but a long start-up time or high start-up costs."

${ }^{8}$ The methods include exhaustive enumeration, dynamic programming, mixed-integer programming, Lagrangian relaxation, and artificial neural networks. See Sheble and Fahd (1994) for an overview of the literature.
}

this will understate the welfare loss, for both the intertemporal and static models. To address this, I also develop a counterfactual set of prices that are consistent with prerestructuring behavior.

For the static and intertemporal models, the paper calculates bounds on the welfare losses associated with restructuring the PJM market. As a lower bound, the welfare estimates based on observed prices imply that actual costs exceeded the intertemporal model's estimates by only $3 \%$. This is substantially less than the predictions generated using the static competitive benchmark analysis technique $(13 \%)$.

As discussed below, the welfare estimates based on conservative estimates of competitive prices provide upper bounds of the deadweight loss. Using these predicted prices, I estimate greater welfare loss for both the intertemporal (8\% of production costs) and static (21\%) models. With either set of prices, I find that the static model overstates welfare effects.

The paper then examines whether these welfare effects are consistent with firms' incentives. Two firms in PJM had incentives to increase prices in the summer of 1999 (Mansur, 2007). I find that, relative to the output decisions predicted with the intertemporal model for the postrestructuring period, these oligopolists produced less while the other pricetaking "fringe" firms produced more. The welfare effects are similarly distributed. Namely, for the strategic firms, actual production costs were \$17-37 million, or $5 \%$ to $10 \%$, less than those predicted by the intertemporal model. In contrast, actual production costs were $\$ 79-121$ million, or $7 \%$ to $11 \%$, greater for the fringe firms.

I conclude that restructuring the PJM market did result in welfare loss, most likely owing to wholesalers' exercising market power. Using my intertemporal model, I estimate that these losses were between $3 \%$ and $8 \%$ of total variable costs during the first summer after the market was restructured. In contrast, the static model overstates welfare loss by about threefold. That model predicts losses between 13\% and $21 \%$.

Section II briefly outlines the PJM wholesale electricity market. Section III defines the optimization problem of competitive firms while accounting for intertemporal constraints. Section IV explains the econometric technique and data used in estimating the intertemporal model. Then, section $\mathrm{V}$ discusses the static model. In section VI, 1 compare how well the models predict observed behavior prior to restructuring. Section VII examines the welfare impacts of market imperfections due to restructuring. The section compares actual production costs with those computed with the intertemporal and static models. Section VIII discusses the consistency of the welfare effects with firms' incentives and section IX concludes. 


\section{The PJM Electricity Market}

\section{A. Market Rules}

In the late 1990s, the PJM Interconnection LLC consisted of most or all of Pennsylvania, New Jersey, Maryland, Delaware, and the District of Columbia, as well as some of Virginia. While integrated with the eastern U.S. transmission grid, the market has been regulated as a single entity based on transmission reliability concerns. In 1997, PJM began facilitating trades among regulated utilities and independent producers by establishing a spot market. The market uses a uniform-price sealed-bid auction for the right to supply power. Firms offer flexible bid curves on a dayahead basis. This study focuses on the summers of 1998 and 1999. During this period, firms had no obligation either to produce or to otherwise cover a bid if they made offers to supply electricity. ${ }^{9}$ In 1998 , PJM adopted what is known as a "nodal" pricing system to account for transmission capacity constraints. ${ }^{10}$

When the nodal market first opened, suppliers were required to make "cost-based" bids for each generating unit. In other words, the producers had to bid their marginal costs of production that had been determined by years of regulatory rate hearings. A notable step in restructuring PJM occurred in April 1999, when the requirement on the energy bid component was relaxed. The Federal Energy Regulatory Commission granted firms the right to change generating units from making cost-based bids to offering a more flexible type of bid. These "market-based" bids were subject to a price cap of $\$ 1,000$ per megawatt-hour (MWh).

\section{B. Market Structure}

While most utilities obtained the right to bid units as market based, many of the generating units continued to be offered as cost-based bids during most of the summer of 1999. Firms may have opted not to switch if they had little incentive to exercise market power. In particular, those firms that either purchased electricity in the market or supplied their own generation may have less of an incentive to increase wholesale prices. The degree of vertical integration of PJM firms helps explain their incentives and behavior. ${ }^{11}$

The large PJM firms are vertically integrated; they generate electricity and have obligations to provide power to

\footnotetext{
9 The PJM Market Monitoring Unit (2000) wrote the following about PJM in 1999: "During the time period covered by this report, unit offers and PJM's day-ahead scheduling did not constitute or create binding financial commitments to provide a defined amount of energy at a defined price."

${ }^{10}$ Each node is a point where energy is supplied, demanded, or transmitted. When congestion occurs, the PJM energy market can have over 2,000 prices. For more on nodal pricing, see Schweppe et al. (1988). In the summers of 1998 and 1999, the transmission system was constrained about $15 \%$ and $18 \%$ of the hours, respectively.

${ }^{11}$ Mansur (2007) discusses this issue in greater detail. The discussion below summarizes the market structure and firms' incentives that are outlined in that paper.
}

retail customers. These firms had to provide exogenously determined quantities of retail obligations (or "native load") at fixed rates. The greater the retail obligation, the less incentive a firm has to set high prices. The objective function (assuming quantity-setting behavior) for vertically integrated firm $i$ can be written

$$
\max _{q_{i}} P_{i}\left(q_{i}\right) \cdot\left(q_{i}-q_{i}^{d}\right)+r_{i}^{d} q_{i}^{d}-C_{i}\left(q_{i}\right),
$$

where $P_{i}\left(q_{i}\right)$ is the inverse residual demand function that firm $i$ faces in the spot market, $q_{i}$ is its production, $r_{i}^{d}$ and $q_{i}^{d}$ are the retail price and native load, and $C_{i}\left(q_{i}\right)$ is total production costs. The resulting first-order condition implies

$$
P_{i}+P_{i}{ }^{\prime} \cdot\left(q_{i}-q_{i}^{d}\right)=C_{i}{ }^{\prime},
$$

where firms have incentives to increase prices only if they are net sellers: $q_{i}>q_{i}^{d}$.

While most firms remained nearly completely integrated after restructuring, two firms, PECO and PPL, were large net sellers and thus had incentives to exercise oligopoly power by raising wholesale prices. The reason for this variation in firms' net positions is due, in part, to differences in state policies. PECO and PPL are located in Pennsylvania, where regulators enacted an aggressive retail choice policy that rewarded customers for leaving their historic providers. These firms were no longer completely integrated and, because of regulatory action, were large net sellers in the wholesale market. In other states in the PJM region, which did not follow such a policy, customers stayed with their incumbent utilities.

For each of the eight major utilities in PJM, panel A of table 1 shows the shares of capacity, generation, peak generation, and demand served. For both PECO and PPL, the share of peak generation is about double their shares of retail customers' demand served. In contrast, Public Service Electric \& Gas (PSE\&G) had a slightly larger share of demand than of generation, on average. Thus, PSE\&G benefits from lower prices and would exercise its oligopsony power by producing from units with marginal costs above price. This behavior would lower the market price. The other firms, including the largest producer, GPU, had similar market shares of peak generation and demand served. For these firms, the first-order condition is close to that of a pricetaking firm $\left(P_{i}=C_{i}{ }^{\prime}\right)$.

Using a difference-in-differences method, Mansur (2007) tests the importance of vertical integration in understanding firm behavior in the PJM market. The study finds that PECO and PPL did produce significantly less than other firms after restructuring. ${ }^{12}$ In section VIII, I compare actual production

\footnotetext{
${ }^{12}$ In a news article, Smith and Fialka (1999) corroborate this finding. They describe the bidding behavior of PECO and PPL as making "the most of steamy conditions."
} 
TABLE 1.-PJM FiRM CHARACTERISTICS

\begin{tabular}{|c|c|c|c|c|c|c|}
\hline \multicolumn{7}{|c|}{ Panel A: Market Shares of Capacity, Generation, and Demand by Firm in Summer of 1999a } \\
\hline Firm & Capacity & & Generation $^{\mathrm{b}}$ & Peak & & $\begin{array}{l}\text { Demand } \\
\text { Served }^{d}\end{array}$ \\
\hline Public Service Electric & $18.1 \%$ & & $14.0 \%$ & & & $17.3 \%$ \\
\hline PECO & $16.7 \%$ & & $17.8 \%$ & & & $8.8 \%$ \\
\hline GPU, Inc. & $16.7 \%$ & & $19.8 \%$ & & & $14.7 \%$ \\
\hline PPL, Inc. & $15.1 \%$ & & $15.9 \%$ & & & $9.9 \%$ \\
\hline Potomac Electric Power & $11.5 \%$ & & $10.1 \%$ & & & $10.4 \%$ \\
\hline Baltimore Gas \& Electric & $10.2 \%$ & & $12.5 \%$ & & & $11.2 \%$ \\
\hline Delmarva Power \& Light & $4.3 \%$ & & $3.2 \%$ & & & $6.0 \%$ \\
\hline Atlantic City Electric & $2.3 \%$ & & $1.1 \%$ & & & $4.3 \%$ \\
\hline Other & $5.1 \%$ & & $5.6 \%$ & & & $17.4 \%$ \\
\hline \multicolumn{7}{|c|}{ Panel B: Generation Capacity by Firm and Fuel Type in $1999^{e}$} \\
\hline Firm & Coal & Oil & Gas & Water & Nuclear & Total \\
\hline Public Service Electric ${ }^{f}$ & 1,607 & 1,842 & 3,311 & - & 3,510 & 10,269 \\
\hline PECO & 895 & 2,476 & 311 & 1,274 & 4,534 & 9,490 \\
\hline GPU, Inc. & 5,459 & 1,816 & 203 & 454 & 1,513 & 9,445 \\
\hline PPL, Inc. & 3,923 & 478 & 1,701 & 148 & 2,304 & 8,554 \\
\hline Potomac Electric Power & 3,082 & 2,549 & 876 & - & - & 6,507 \\
\hline Baltimore Gas \& Electric & 2,265 & 925 & 755 & - & 1,829 & 5,773 \\
\hline Delmarva Power \& Light & 1,259 & 888 & 311 & - & - & 2,458 \\
\hline Atlantic City Electric & 391 & 436 & 482 & - & - & 1,309 \\
\hline Otherg & 2,087 & 353 & - & 439 & - & 2,880 \\
\hline Total & 20,967 & 11,762 & 7,949 & 2,316 & 13,690 & 56,685 \\
\hline Market share & $37 \%$ & $21 \%$ & $14 \%$ & $4 \%$ & $24 \%$ & \\
\hline \multicolumn{7}{|c|}{$\begin{array}{l}\text { Notes: } \\
\text { (a) Summer is defined as April } 1 \text { to September } 30 . \\
\text { (b) Source: Energy Information Administration (EIA) form 759, 1999. I aggregate monthly generation for April through September. } \\
\text { (c) Source: EPA Continuous Emissions Monitoring System, 1999. Peak generation share is share during hours with demand above } 40,000 \mathrm{MW} \text {. } \\
\text { (d) Demand served is share summer peak demand less direct access customers. On July 6, 1999, the systemwide demand reached a peak of } 51,700 \mathrm{MW} \text {. Source: EIA form } 861 \text {, 1999. In 1999, many Pennsylvania } \\
\text { ustomers switched to alternative providers, leaving GPU (3.4\% of total market demand), PECO }(5.6 \%) \text {, and PPL (2.5\%). "Other" demand includes direct access customers. Source: http://www.oca.state.pa.us. } \\
\text { (e) In 1999, the GPU parent company owned Jersey Central, GPU Nuclear, Metropolitan Edison, and Pennsylvania Electric. } \\
\text { (f) "Other" includes the following utilities: Safe Harbor Water Power, Easton Utilities, UGI Development, Allegheny Electric Co-op, A\&N Electric Co-op, and the cities of Berlin, Dover, Lewes, Seaford, and } \\
\text { ineland. I also include Edison, which purchased Homer City from GPU in March 1999. } \\
\text { (g) Capacity, in megawatts (MW), is listed by primary fuel type used in each generating unit at a power plant, as determined by the EIA. Coal includes anthracite, bituminous coal, and petroleum coke. Oil includes } \\
\text { os. 2, 4, and } 6 \text { fuel oil and kerosene. The other categories are natural gas, hydroelectric, and nuclear. Source: EIA form } 860,1999 \text {. }\end{array}$} \\
\hline
\end{tabular}

decisions with those of the intertemporal model to test whether behavior is consistent with the incentives of firms.

\section{Electricity Prices and Restructuring}

Prices increased substantially from the summer of 1998 to the summer of 1999. From April through September 1998 , the average of the actual prices was $\$ 26.04$ per MWh. The following summer, the average price was $\$ 37.97$ per MWh. ${ }^{13}$

These higher wholesale electricity prices are partially explained by higher input prices in the summer of 1999 than in the previous summer. Average natural gas prices increased from $\$ 2.33$ to $\$ 2.60$ per mmBTU. ${ }^{14}$ Average oil prices went from $\$ 16.30$ to $\$ 20.56$ per barrel. ${ }^{15}$ Tradable permits for sulfur dioxide emissions increased from $\$ 172.44$

${ }^{13}$ Electricity price data are from PJM Interconnection. See http://www. pjm.com.

${ }^{14}$ Data on natural gas prices at Transco Zone 6 non-New York are from the Natural Gas Intelligence.

${ }^{15}$ No. 2 heating oil sold at New York Harbor data are from the U.S. Energy Information Administration (EIA). per ton in the summer of 1998 to $\$ 202.71$ per ton in the following summer. ${ }^{16}$

In addition, environmental regulation of nitrogen oxides began in the summer of 1999. Tradable permits for the Ozone Transport Commission regulation started near $\$ 5,000$ per ton but fell dramatically to under $\$ 1,000$ per ton by the end of the summer. For each ton emitted from May through September, firms were required to have an offsetting permit by the end of the year.

Increases in input costs, which were also accompanied by greater demand for electricity, will result in higher prices in a competitive market. Using a method similar to BBW, Mansur (2007) simulates competitive prices during the summers of 1998 and 1999. During the summer of 1998, the simulations of the competitive prices were quite similar to the observed prices. The mean of the simulated competitive prices was $\$ 25.93$ per MWh, or 11 cents below the observed average price. In contrast, the predicted competitive prices averaged $\$ 32.33$ per MWh in the summer following restruc-

${ }^{16}$ EPA reports monthly average trades of sulfur dioxide permits at two brokerage firms: Cantor Fitzgerald and Fieldston. I report the mean of the monthly prices. 
Figure 1.-PJM Supply CuRve (April 1, 1999)

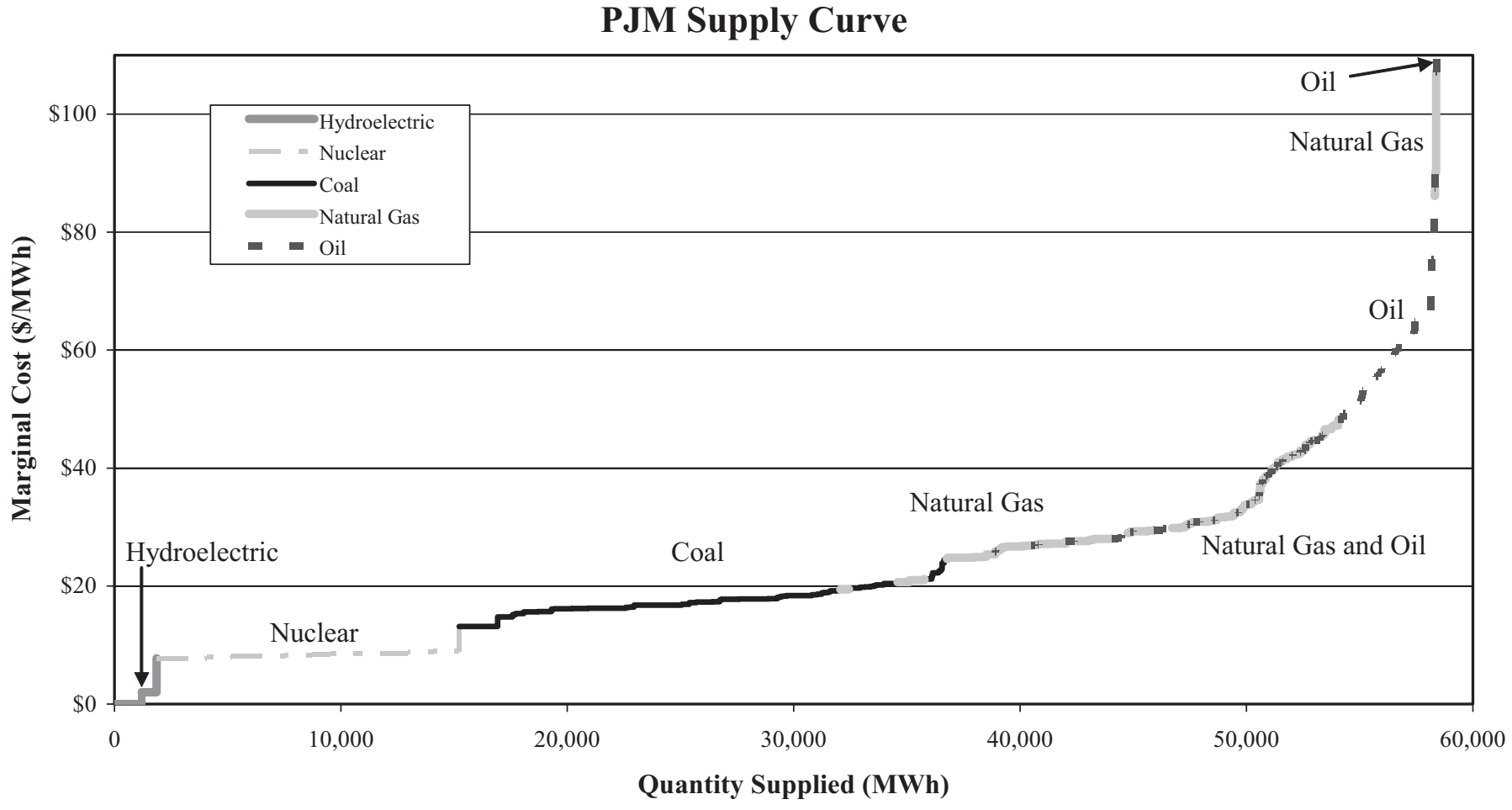

turing. While greater than the competitive price in the summer of 1998 , this is approximately $\$ 5.64$ per $\mathrm{MWh}$ below the actual average price during the summer of 1999 . Hence, Mansur finds evidence of market imperfections after restructuring but not before restructuring.

\section{Power Plant Characteristics}

For each of the major firms, panel B of table 1 reports 1999 generation capacity categorized by primary fuel type. Firms produce electricity using a variety of technologies, which is in part due to the longevity of outdated power plants. Furthermore, because of current technological limits on the storage and production of electricity, even a new generation system would require a mix of technologies. "Baseload" generating units operate at low marginal costs most hours. More flexible "peaking" units operate at high marginal costs just a few hours a day.

In 1999, the market consisted of approximately 57,000 megawatts (MW) of capacity, including nuclear, hydroelectric, coal, natural gas, and oil energy sources (see figure 1). Nuclear and coal plants provide baseload generation capable of covering most of the demand. Nuclear power comprises $45 \%$ of generation but only $24 \%$ of capacity. In contrast, natural gas and oil burning units provide over a third of the market's capacity, yet they operate only during peak demand times. These differences in utilization result from heterogeneous cost structures. Baseload units have low marginal costs and significant intertemporal constraints, like large start-up costs, while the relatively flexible peaking units are more expensive to operate. The next section discusses how these constraints enter into a competitive firm's optimization problem.

\section{Intertemporal Model of Competitive Production}

Pricetaking firms obtain profit maximization by optimizing each unit's production separately. In contrast, a strategic firm will consider how much is being produced at other plants. The more that is being produced at other plants, the more a strategic firm will profit by reducing output from the competitive level in order to increase prices (Wolfram, 1998). In addition, a strategic firm will consider the quantity that it committed to sell under long-term financial contracts with fixed rates (Wolak, 2000). For a firm taking prices as given, neither a firm's production at other plants nor its contractual agreements affect optimization. This section examines the optimization problem for a firm that takes prices as given and faces non-convexities in costs.

Several technologically induced intertemporal constraints limit a firm's ability to produce electricity. As previously mentioned, after unit $i$ shuts down, in order to resume operation at hour $t$, the firm incurs "start-up" costs $\left(S T A R T_{i}\right)$. Ramping rates $\left(R_{i}\right)$ limit the speed at which units change hourly production, that is, how much output can be changed in one hour. Constraints on minimum load $\left(M I N_{i}\right)$ limit how little a unit can generate without shutting down. These intertemporal constraints create non-convexities in firms' 
production cost functions. ${ }^{17}$ To fix ideas, I begin with a simplified unit commitment problem.

I model the firm operating unit $i$ as solving a deterministic, discrete-time dynamic program. ${ }^{18}$ The state variable, $S_{i t}$, equals the level of production going into period $t$. The choice variable, $x_{i t}$, equals the change in the level of production in period $t$. The law of motion of $S_{i t}$ is similar to the literature on extraction of nonrenewable resources where $x_{i t}$ represents the change in the state variable: $S_{i t}+x_{i t}=S_{t+1}$.

The value function, $V\left(S_{i t}\right)$, depends on several parameters. I assume that firms take price, $P_{t}$, as given. Variable costs are assumed to be linear such that $c_{i t}$ is a constant marginal cost of production. Capacity, $C A P_{i}$, restricts unit $i$ 's maximum range of operation. The discount factor is $\delta$. Given these parameters and the intertemporal constraints $S T A R T_{i}, R_{i}$, and $M I N_{i}$, the Bellman equation equals

$$
\begin{aligned}
V\left(S_{i t}\right)= & \max _{x_{i t} \in\left[-R_{i}, R_{i}\right]}\left(P_{t}-c_{i t}\right) \cdot\left(x_{i t}+S_{i t}\right) \\
& -f\left(x_{i t}, S_{i t}\right) \cdot S T A R T_{i}+\delta V\left(x_{i t}+S_{i t}\right) \\
& \text { s.t. }: x_{i t}+S_{i t} \geq g\left(x_{i t}, S_{i t}\right) \cdot M I N_{i}, \\
& \text { and } x_{i t}+S_{i t} \leq C A P_{i},
\end{aligned}
$$

where $f\left(x_{i t}, S_{i t}\right)$ indicates starting and $g\left(x_{i t}, S_{i t}\right)$ indicates continuing to operate:

$$
\begin{aligned}
& f\left(x_{i t}, S_{i t}\right)=\left\{\begin{array}{l}
1 \text { if } x_{i t}>0 \text { and } S_{i t}=0 \\
0 \text { else, }
\end{array}\right. \text { and } \\
& g\left(x_{i t}, S_{i t}\right)=\left\{\begin{array}{l}
1 \text { if } x_{i t}+S_{i t}>0 \text { and } S_{i t}>0 \\
0 \text { else }
\end{array}\right.
\end{aligned}
$$

Intertemporal constraints may reduce a unit's true marginal cost; for example, postponing shutting down at low prices may improve overall profits since the firm avoids restarting the unit later on when prices rise. Intertemporal constraints may also increase marginal costs. Again, using the case of start-up costs, a firm will not operate even when prices exceed marginal costs of production if rents are not substantial enough to cover the cost of starting.

If intertemporal constraints are inconsequential, then the optimization problem for pricetaking firms can be further simplified. As the optimization problem is no longer state

\footnotetext{
17 There are other intertemporal constraints as well. For example, a unit may have to remain operating for some time once it starts before it can be shut down. Conversely, a unit may have to remain off a certain amount of time before restarting. There may be some costs that the firm incurs regardless of the amount produced (for example, operating fans and conveyor belts).

18 This model differs from engineering models. Here, I take prices as exogenous. Typically, engineers solve for the least cost manner to meet the quantity demanded and solve for the price, or "system lambda."
}

dependent, I define the choice variable $q_{i t}=x_{i t}+S_{i t}$. For each period $t$, the optimization problem is

$$
\max _{q_{i t} \in\left[0, C A P_{i}\right]}\left(P_{t}-c_{i t}\right) q_{i t}
$$

With no intertemporal constraints, these firms operate units at full capacity when price exceeds (or equals) marginal cost. Otherwise, they do not produce. This is referred to as the static competitive benchmark analysis model and is explored in section V. Given this description of competitive firms' optimization problem, the following section explains the method used to account for intertemporal constraints in order to determine a competitive counterfactual market outcome.

\section{Method for Estimating Intertemporal Model}

\section{A. Econometric Model}

In this section, I develop a method for estimating competitive behavior for the post-restructuring period while accounting for intertemporal constraints. First, I estimate the firms' production decisions using data from a period before restructuring. The coefficient estimates from the regression are used to predict production both in the prerestructuring period of 1998 and for the post-restructuring period of 1999. A key identifying assumption is that, before restructuring, firms behaved competitively by taking prices as given and minimizing costs.

I argue that, while power plants were regulated in 1998, their short-run operations were consistent with competitive behavior. Surely this regulated market did not exemplify perfect competition. Firms invested inefficiently and probably distorted marginal costs of production by making inefficient decisions regarding maintenance, labor, and capital allocation including pollution abatement technologies. However, given these costs, operators likely dispatched units in a least-cost manner. ${ }^{19}$ As previously mentioned, Mansur (2007) finds simulated prices that are close to actual prices, on average, for the summer of 1998. These findings support the claim made in this paper: in 1998, firm behavior was consistent with that of a competitive market.

\footnotetext{
${ }^{19}$ Under regulation, some argue that firms had incentives to minimize effort rather than costs and therefore did not operate efficiently. Firms may have let units operate during low-demand times instead of stopping and restarting them. If restructuring improved efficiency then, conditional on market conditions, more starts would be expected in the summer of 1999 than in that of 1998. Without controlling for market conditions, the number of starts for the units in my sample decreased from 3,970 to 3,846.

Furthermore, even in 1998, firms could have withheld production from units that would have operated in a competitive market. However, as cost-based bids determined prices, the ability to move prices may have been limited. In contrast, in 1999, the flexibility of using bids as well as quantity may have facilitated exercising market power to the degree that firms circumvented constraints, such as regulatory surveillance. In addition, these historically regulated utilities may have undergone a learning process about how to exercise market power.
} 
Unlike production models that estimate the optimal mix of inputs, production costs are known in this case. Rather, I estimate how constraints affect the firm's dynamic optimization problem. An alternative approach would be to make a direct calculation of the dynamically optimal solution. However, this would require information on the exact method the system operators use to dispatch units and on the ways firms form expectations about future prices. This paper proposes an approach that econometrically estimates the relationship between output decisions and firm and industry characteristics. ${ }^{20}$

Based on equation (3), I assert that a pricetaking firm will choose current output as a function of historic, current, and future price-cost markups, as well as intertemporal constraints. I estimate a descriptive model of output $\left(q_{i t}\right)$ at unit $i$ during hour $t$. A firm produces more given greater current price-cost markups $\left(\mathrm{pcm}_{i t}=P_{t}-c_{i t}\right)$. My model incorporates the static model by including an indicator variable of positive markups $\left(\mathrm{pcm}_{-} \mathrm{pos}_{i t}\right)$. If the static model is correct, this variable should fully explain production decisions. In addition, I include a linear term of $p c m_{i t}$.

If the firm expects prices to increase in the near future, it may also increase production now. Therefore, I include markups for the following hour: $\mathrm{pcm}_{i, t+1}$. Also, if a firm is slow to adjust, it may consider average markups $\left(\overline{p c m}_{i t}\right)$ for today and tomorrow. Furthermore, if markups were recently high, the firm may have chosen a high value of $S_{i t}$ and is more likely to be operating. Therefore, greater markups in the recent past will also be important in determining current production, so the model includes hourly-lagged markups, $p c m_{i, t-1}$, and yesterday's average markup, $\overline{p c m}_{i, t-24}$.

Other characteristics (like start-up costs, ramping rates, minimum load, and unit capacity) do not vary by time. They cannot be separately identified from an idiosyncratic unit fixed effect. ${ }^{21}$ Furthermore, these characteristics are likely to impact how firms respond to the series of price-cost markups. Therefore, I allow the coefficients on the pricecost markups to differ by unit as well as include unit fixed effects $\left(\alpha_{i}\right)$.

Recall that this is a model of a competitive market and is based on observed behavior in the pre-restructuring period of $1998\left(q_{i t}^{p r e}\right)$. Therefore, I do not take into consideration strategic variables, such as output at other plants. For the pre-restructuring period, I define $X_{i t}$ as the set of independent variables, namely the seven measures of price-cost

\footnotetext{
${ }^{20}$ Unlike a dynamic model, the method I use does not make assumptions on how firms make forecasts of future prices. Rather, I test whether there is a correlation between future prices and production behavior.

${ }^{21}$ Note that the other unit commitment issues mentioned in footnotes 7 and 17 (such as minimum up times, minimum down times, no load costs) are also unit specific and will be captured by the unit fixed effect in similar manner. Thus, this method addresses all unit commitment problems that either do not vary over time or are correlated with price-cost markups.
}

markups mentioned above. The resulting econometric model is

$$
q_{i t}^{p r e}=\alpha_{i}^{p r e}+\beta_{i}^{p r e} \cdot X_{i t}^{p r e}+\varepsilon_{i t}^{p r e} .
$$

More explicitly, I model output in the pre-restructuring period as

$$
\begin{aligned}
& q_{i t}=\alpha_{i}+\beta_{1, i} p c m_{-} \text {pos }_{i t}+\beta_{2, i} p c m_{i t}+\beta_{3, i} p c m_{i, t-1} \\
& +\beta_{4, i} p c m_{i, t+1}+\beta_{5, i} \overline{p c m}_{i t}+\beta_{6, i} \overline{p c m}_{i, t-24} \\
& +\beta_{7, i} \overline{p c m}_{i, t+24}+\varepsilon_{i t} .
\end{aligned}
$$

To allow for a flexible form, all variables (except the fixed effects and pcm_pos ${ }_{i t}$ indicators) are estimated as fifth-order polynomial functions. This data-fitting method is designed for predictive power. For each of the 130 units, I separately estimate ordinary-least-squares coefficients and NeweyWest (1987) heteroskedasticity and autocorrelation consistent standard errors (assuming a 24-hour lag structure).

I use the coefficient estimates from pre-restructuring $\left(\alpha_{i}^{\text {pre }}, \hat{\beta}_{i}^{\text {pre }}\right)$ to determine a competitive counterfactual of production $\left(\hat{q}_{i t}\right)$ both in sample, for 1998:

$$
\hat{q}_{i t}^{\text {pre }}=\hat{\alpha}_{i}^{\text {pre }}+\hat{\beta}_{i}^{\text {pre }} \cdot X_{i t}^{\text {pre }},
$$

and also out of sample for the post-restructuring period of 1999:

$$
\hat{q}_{i t}^{\text {post }}=\hat{\alpha}_{i}^{\text {pre }}+\hat{\beta}_{i}^{\text {pre }} \cdot X_{i t}^{\text {post }} .
$$

Some of the predicted output levels, $\hat{q}_{i t}$, are not plausible and are truncated. For example, if the predicted value is below 0 , then I truncate the prediction at 0 because this is a physical constraint. As discussed in the data section below, I define capacity as the maximum observed amount of production in either 1998 or 1999. If the predicted value is greater than capacity, then I truncate at this amount.

\section{B. Caveats on the Estimation Method}

First, regressing output on price-cost markups will result in biased coefficients if either prices or marginal costs are endogenous. However, recall that the coefficients are estimated for 1998 only, before the market was restructured. As mentioned above, during this period, firms' behavior is assumed to be consistent with that of a competitive market: I assume firms cannot change the price. Furthermore, as discussed below, the marginal cost of production is assumed to be constant for a given unit and a given day. Increasing output may increase a firm's marginal cost as it operates more expensive units, but the marginal cost of production for a given unit will not change. For these reasons, I can estimate equation (8) using ordinary least squares.

Second, I assume that the relationship between output and markups would not have changed had restructuring not 
occurred. Furthermore, I place bounds on the welfare estimates. For the lower bound, I assume that the price-cost markups $\left(X_{i t}^{\text {post }}\right)$ would not have changed from the observed levels had restructuring not occurred. In other words, the null hypothesis, in this case, is that restructuring did not result in market power. If firms did set high prices in 1999, these estimates will overstate production and therefore overstate costs. This places a lower bound on the welfare effects of a given model but will not necessarily bias the relative welfare effects of the intertemporal and static models. I define the upper bound by constructing conservative estimates of prices that are consistent with competition.

Third, this reduced-form method requires a common support of the exogenous variables. In both summers, actual prices ranged from $\$ 0$ to $\$ 999$ per MWh. While the high prices were more frequent after restructuring, there were some times when prices were extremely high before restructuring, potentially reflecting scarcity rents. The range of hourly price-cost markups were quite similar pre- and postrestructuring. ${ }^{22}$

\section{Data}

The intertemporal model requires data on hourly prices, actual hourly unit-level production, and daily unit-level marginal costs. PJM reports quantity-weighted average nodal hourly prices. The EPA's Continuous Emissions Monitoring System (CEMS) provides actual hourly gross generation for most fossil fuel-burning units. ${ }^{23}$ Gross generation includes the electricity generated for sales (net generation) as well as the electricity produced to operate that power plant. Typically, net generation is $90 \%$ to $95 \%$ of gross generation. CEMS data are highly accurate and comprehensive for most types of fossil units (Joskow \& Kahn, 2002). Throughout this analysis, I define my sample to be a panel of the 130 units in the CEMS data that operated during both summers. These units account for approximately $92 \%$ of the fossil generation in PJM. ${ }^{24}$

\footnotetext{
${ }^{22}$ In my sample, the markups faced by all generating units (regardless of whether they operated or not) ranged from $-\$ 114$ to $\$ 986$ per MWh in the pre-restructuring summer. They averaged $-\$ 1.92$ per MWh. After restructuring, the markups ranged from $-\$ 134$ to $\$ 984$ per $\mathrm{MWh}$ and averaged $\$ 4.79$ per MWh. Conditional on operating, the pre-restructuring markups ranged from $-\$ 87$ to $\$ 986$ per MWh (and averaged $\$ 7.09$ per MWh). The post-restructuring markups ranged from $-\$ 121$ to $\$ 984$ per MWh (and averaged $\$ 21.16$ per $\mathrm{MWh}$ ).

${ }^{23}$ CEMS records hourly gross production of electricity, heat input, and three pollutants - sulfur dioxide, nitrogen oxides, and carbon dioxide-for most fossil units in the country. During the summers of 1998 and 1999 CEMS monitored 234 units that accounted for over 97\% of PJM's fossil fuel capacity. In order to comply with the 1990 Clean Air Act, fossil fuel-generating electric producers are required to report hourly emissions and electricity production by unit. Regulation affects units of $25 \mathrm{MW}$ capacity plus new units under $25 \mathrm{Mw}$ that use fuel with a sulfur content greater than $0.05 \%$ by weight.

${ }^{24}$ During the summer of 1998 , the units in the sample produced on average 16,653 gross MWh per hour (or approximately 15,820 net MWh per hour). According to the EPA's eGRID database, fossil units produced an average of 17,237 net MWh per hour in 1998 .
}

I calculate marginal costs using a typical engineering formula based on years of regulation. A unit's marginal cost of production up to capacity $\left(c_{i t}\right)$ is independent of production:

$$
c_{i t}=V O M_{i}+H R_{i} \cdot\left(W_{i t}^{f u e l}+W_{i t}^{S O_{2}} r_{i}^{S O_{2}}+W_{i t}^{N O_{x}} r_{i}^{N O_{x}}\right),
$$

where $V O M_{i}$ is variable operating and maintenance cost and $H R$ is an efficiency measure called heat rate. ${ }^{25} W_{i t}^{f u e l}, W_{i t}^{S O_{2}}$, and $W_{i t}^{N O_{x}}$ are daily prices for unit $i$ 's fuel usage, sulfur dioxide emissions, and nitrogen oxides emissions, respectively. $r_{i}^{\mathrm{SO}_{2}}$ and $r_{i}^{\mathrm{NO}}{ }_{x}$ are emissions rates. I merge production data with data on unit characteristics and input prices. ${ }^{26} \mathrm{I}$ define capacity $\left(C A P_{i}\right)$ as the maximum observed gross production over the summers of 1998 and 1999.

\section{Static Competitive Benchmark Analysis}

The static competitive benchmark analysis counterfactual assumes no intertemporal constraints. As with section IV, the null hypothesis in this section is that, post-restructuring, firms continued to take prices as given. Thus, I assume that the $N$ units in my sample would have produced the same

\footnotetext{
${ }^{25}$ Constant marginal costs is an assumption. As power plants increase output, they run more efficiently and the heat rate falls, thereby reducing the marginal cost. To test the importance of this assumption, I look at the variation in hourly heat rates reported in the CEMS data. For the PJM generating units during the summers of 1998 and 1999, I regress hourly heat rates on unit fixed effects. Overall, the fixed effects explain only $8 \%$ of the variation. However, this is primarily due to some extreme outliers. Dropping the lowest and highest $1 \%(5 \%)$ of the heat rates, the fixed effects explain about $60 \%(70 \%)$ of the variation. Similarly, because of locational marginal pricing, the price a firm would earn may differ slightly from the load-weighted average price that I use in the study. As mentioned in footnote 10, about a sixth of the hours in my sample exhibit congestion. However, during this time period, congestion did not result in large price differences, on average, within PJM (see http://www.pjm.com). I conclude that the errors-in-variables problem from incorrectly measuring price-cost markups is likely to be small.

${ }^{26}$ PROSYM (Kahn, 2000) provides data on heat rate, coal costs, sulfur dioxide emissions rates, nitrogen oxides emissions rates, and variable operating and maintenance costs. I measure fuel prices using spot prices of oil and natural gas while assuming constant coal costs. The Energy Information Administration (EIA) provides data on the daily spot price of New York Harbor no. 2 heating oil and BTU/gallon conversion rates. Natural Gas Intelligence provided daily natural gas spot prices for Transco Zone 6 non-New York. For oil and natural gas units, I add fuel distribution costs that I approximate as the difference between the average spot price in the region and the price PJM firms report for delivered fuel over the summers of 1998 and 1999 (EIA form 423, 1998 and 1999). Unit-specific coal prices are from Kahn (2000). To calculate $\mathrm{SO}_{2}$ regulation costs, I use the mean of two monthly price indices of $\mathrm{SO}_{2}$ permit prices that brokerage firms Cantor Fitzgerald and Fieldston report to the EPA. The EPA lists which units had to comply with the Acid Rain program during Phase I (including "substituting" units). Few firms traded in the new $\mathrm{NO}_{x}$ permits when it first opened. In fact, they had until the end of the year to "true up" their allowances with actual emissions. About once a month, Cantor Fitzgerald reports data on $\mathrm{NO}_{x}$ prices, which started near $\$ 5,000 /$ ton in May and ended around \$1,000/ton in September. By November, the price had fallen to $\$ 723 /$ ton. I define the $\mathrm{NO}_{x}$ price to be $\$ 2,000 /$ ton, which is approximately the average of the $\mathrm{NO}_{x}$ prices from May until December 1999. Plants in Pennsylvania, New Jersey, and Delaware had $\mathrm{NO}_{x}$ regulatory compliance obligations in 1999.
} 
Figure 2.-Measuring Welfare Loss for Static Model

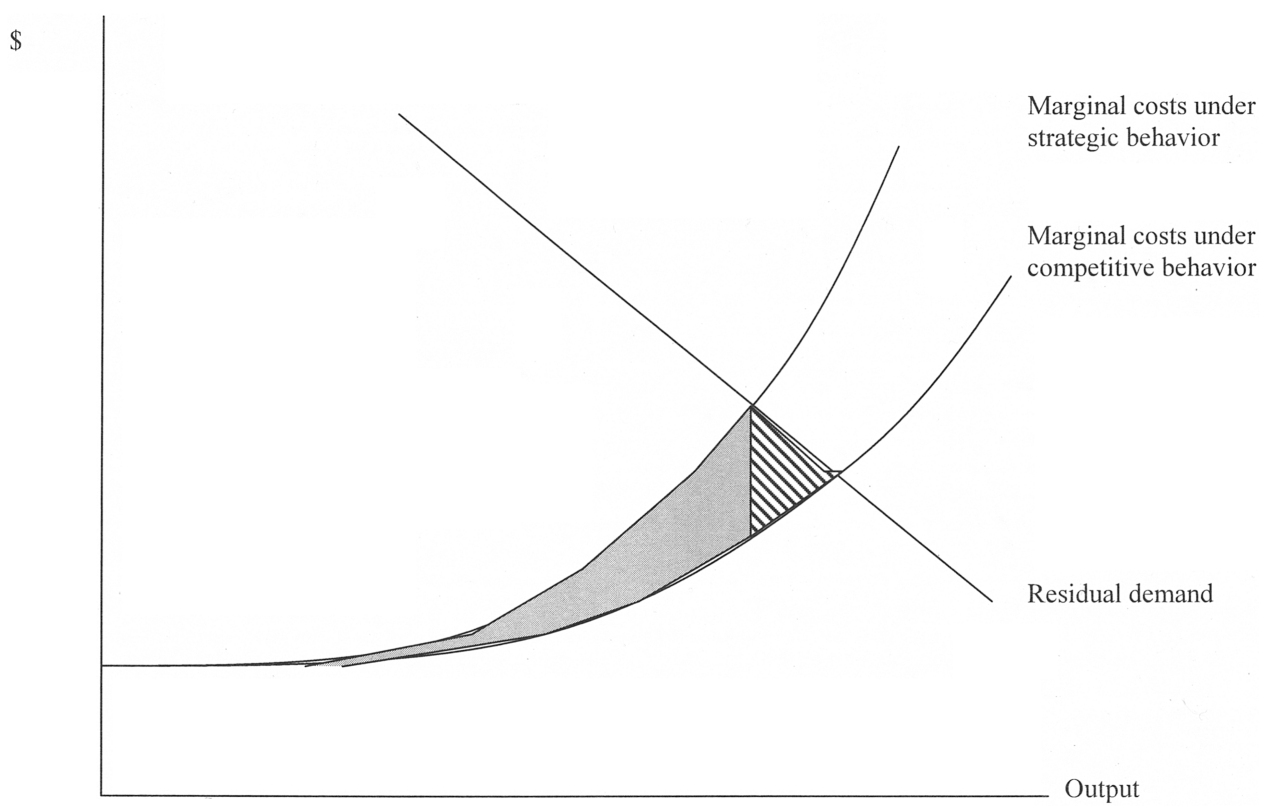

amount, in aggregate, under the static model as they actually generated each hour:

$$
Q_{t}=\sum_{i=1}^{N} q_{i t}=\sum_{i=1}^{N} q_{i t}^{*},
$$

where, for unit $i$ at hour $t, q_{i t}$ is actual production and $q_{i t}^{*}$ is the static competitive counterfactual of production.

Figure 2 depicts the measure of welfare loss for the static model. The figure includes two marginal-cost curves: the marginal-cost curve where strategic firms actually produce and the marginal costs of competitive supply. Residual demand equals the market demand, which is nearly perfectly inelastic, less the response from fringe units.

The fringe is composed of some PJM units that are not in the balanced panel. The EPA does not monitor units that are small or that do not emit air pollution. In addition, some plants did not operate in one of the summers and, therefore, were not in the balanced sample. The fringe also includes plants in areas bordering PJM that export power to PJM. The fringe firms are assumed to be competitive. When firms in the sample exercise market power, the marginal costs are greater because of inefficient production. The welfare loss is (at a minimum) the gray area between the strategic and competitive marginal-cost curves.

Note that if firms exercise market power, then the total amount produced by all strategic firms, $Q_{t}$, will be less than the competitive equilibrium, $Q_{t}^{*}$. By assuming that the competitive output equals the observed level, the gray area ignores the changes in imports and other units not in the sample. This assumption implies that calculations of deadweight loss will be understated. The hashed area in figure 2 accounts for the additional economic gains from competition. In the next section, I measure both the gray and hashed areas: the gray area is measured by using actual prices, while the additional welfare loss is captured using an alternative set of prices that are consistent with a competitive market.

The static technique assumes that the units would be dispatched in order of marginal cost and produce at full capacity. However, whenever a firm attempts to generate using unit $i$, there is some probability, $f_{i}$, that the unit will not be able to operate. As with BBW, this model accounts for these "forced outages" by using Monte Carlo simulations. For each hour in the sample, outages are simulated by drawing $\xi_{i t}$ from a $[0,1]$ uniform distribution. If $\xi_{i t}$ is less than $f_{i}$, the unit cannot operate. For every hour and Monte Carlo simulation, each unit's output is calculated. A unit's hourly production, $q_{i t}^{*}$, equals the mean of 100 simulation draws. See Mansur (2007) for a discussion of the additional data used for this method.

\section{Comparisons of Models}

\section{A. Comparing Predictive Power of Models}

For the pre-restructuring period, table 2 summarizes the results of estimating equation (8). For each variable, I compute the mean of the 130 unit-specific coefficients and their standard errors. As expected, the coefficients on the price-cost margins tend to be positive. The static model variable, pcm_pos, is significant and positive. However, the other variables do have predictive power. I report the number of units for which each coefficient is significant at the 
TABle 2.-Summary of InTERTEMPoral Competitive Model Estimation

DEPENDENT VARIABLE: ELECTRICITY OUTPUT BY UNIT AND HOUR

AVERAGE OF THE COEFFICIENTS, STANDARD ERRORS, AND MARGINAL EFFECTS OVER 130 UNITS

\begin{tabular}{|c|c|c|c|c|}
\hline Variable & $\begin{array}{l}\text { Average of } \\
\text { Coefficients }\end{array}$ & $\begin{array}{l}\text { Average of } \\
\text { Std. Errors }\end{array}$ & $\begin{array}{c}\text { \# of Coefs. } \\
\text { Significant }\end{array}$ & $\begin{array}{c}\text { Marginal } \\
\text { Effects }\end{array}$ \\
\hline fixed effect & 122.83 & 2.40 & 126 & \\
\hline pcm positive & 26.76 & 3.45 & 101 & \\
\hline pcm & -0.06 & 0.27 & 47 & -0.05 \\
\hline pcm2 (times 1,000) & -0.60 & 3.21 & 37 & \\
\hline pcm3 (times 1,000) & 0.00 & 0.01 & 33 & \\
\hline pcm4 (times $10^{6}$ ) & -0.01 & 0.02 & 30 & \\
\hline pcm5 (times $10^{9}$ ) & 0.00 & 0.01 & 28 & \\
\hline pcmlag & 0.44 & 0.19 & 96 & 0.46 \\
\hline pcmlag2 (times 1,000) & -4.02 & 2.44 & 80 & \\
\hline pcmlag3 (times 1,000 ) & 0.01 & 0.01 & 64 & \\
\hline pcmlag4 (times $10^{6}$ ) & -0.02 & 0.01 & 63 & \\
\hline pcmlag5 (times $10^{9}$ ) & 0.01 & 0.01 & 59 & \\
\hline pcmlead & 1.23 & 0.19 & 121 & 1.27 \\
\hline pcmlead2 (times 1,000) & -11.90 & 2.41 & 114 & \\
\hline pcmlead3 (times 1,000) & 0.04 & 0.01 & 109 & \\
\hline pcmlead4 (times $10^{6}$ ) & -0.05 & 0.01 & 106 & \\
\hline pcmlead5 (times $10^{9}$ ) & 0.02 & 0.01 & 102 & \\
\hline avepcm & -0.04 & 0.34 & 21 & 1.41 \\
\hline avepcm2 (times 1,000) & -14.19 & 18.34 & 31 & \\
\hline avepcm3 (times 1,000) & 0.47 & 0.42 & 30 & \\
\hline avepcm4 (times $\left.10^{6}\right)$ & -3.98 & 3.63 & 43 & \\
\hline avepcm5 (times $10^{9}$ ) & 10.00 & 10.09 & 45 & \\
\hline avepcmlag & 0.76 & 0.29 & 44 & 0.42 \\
\hline avepcmlag2 (times 1,000$)$ & -13.99 & 17.18 & 27 & \\
\hline avepcmlag3 (times 1,000$)$ & 0.11 & 0.40 & 25 & \\
\hline avepcmlag4 (times $\left.10^{6}\right)$ & -0.21 & 3.46 & 24 & \\
\hline avepcmlag5 (times $10^{9}$ ) & -0.50 & 9.53 & 25 & \\
\hline avepcmlead & 0.19 & 0.29 & 18 & 1.34 \\
\hline avepcmlead2 (times 1,000) & -17.49 & 17.14 & 21 & \\
\hline avepcmlead3 (times 1,000) & 0.38 & 0.40 & 20 & \\
\hline avepcmlead4 (times $\left.10^{6}\right)$ & -2.88 & 3.40 & 27 & \\
\hline avepcmlead5 (times $10^{9}$ ) & 7.31 & 9.36 & 31 & \\
\hline
\end{tabular}
Notes: Each unit-specific regression includes a constant and an indicator variable of positive current price-cost markups (pcm). The other variables are estimated as fifth-order polynomials. pcmlag is last hour's
$\mathrm{pcm}$, and pcmlead is next hour's pcm. avepcm is the daily average pcm. avepcmlag is yesterday's average pcm, and avepcmlead is tomorrow's average pcm. The unit fixed effect is also shown. The model's $R$-squared is 0.81 .

5\% level. The hourly lead $p c m$ variables are significant for most units, whereas the daily lag $\mathrm{pcm}$ variables are significant for about a third of the units. For each observation, I calculated the marginal effect for each of the six markup variables. The table shows the average of these marginal effects. The average of the marginal effects for the hourly markups are similar to the average of the linear coefficients. However, for the three sets of daily markup measures, the marginal effects differ from the linear coefficients. The hourly and daily lead $\mathrm{pcm}$ terms have large marginal effects, suggesting that firms are considering what future prices are likely to be when making decisions on how much to produce. The model has an $R$-squared of 0.81 .

Next, I compare whether the intertemporal or static model is a better predictor of actual generation in 1998. If intertemporal constraints were unimportant, then the flexible econometric model would not necessarily be better. I normalize generation by capacity to give equal weight to all observations. The ratio of generation to capacity is called the utilization rate. The correlation of actual utilization rates to static utilization rate estimates is 0.61 . In contrast, the correlation of actual utilization rates with intertemporal utilization rate estimates is $0.79 .{ }^{27}$

For the summer before PJM restructured, figure 3 plots a kernel regression of markups ranging from $-\$ 30$ to $\$ 30 /$ MWh on actual utilization rates (black line). ${ }^{28}$ As markups

\footnotetext{
${ }^{27}$ A more formal test requires the use of some non-nested test, since there does not exist a mapping of one utilization rate estimate to the other. I follow the method of an encompassing test, as described in Davidson and MacKinnon (1993). This is done by testing one hypothesis and including the variables from the second hypothesis that are not already in the model. In this case, I regress actual utilization rates on the intertemporal model estimates, and also include the static model's estimates. If one model's predicted values are significant and the other is not, then that model is determined to be the better predictor. As above, I estimate the NeweyWest (1987) standard errors with a 24-hour lag structure. As the independent variables are estimated, I correct the errors using the method suggested by Murphy and Topel (1985). The coefficient on the intertemporal model's estimate is 0.92 (s.e. of 0.01 ). The static model's coefficient is $0.09(0.01)$. While this is smaller in magnitude, it is still significant. Therefore, neither model can be rejected.

${ }^{28}$ These are the 5th and 95th percentiles of the distribution of price-cost markups in the summer of 1998. All units in my sample are included in the analysis. I estimate the kernel regression with Stata's kernregl command. The command computes the Nadaraya-Watson nonparametric regression.
} 
Figure 3.-GoOdNess-OF-Fit COMPARISON OF UTILIZATION Rates across Price-Cost Markup

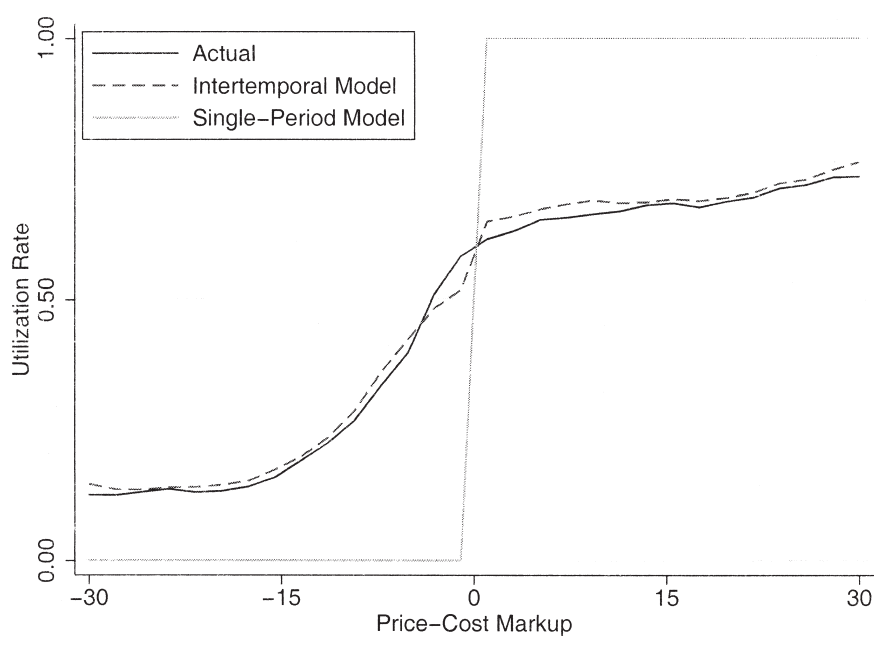

increase, the average utilization rate rises slowly from 0.2 to 0.8. The intertemporal model (the dashed, dark gray line) closely fits observed behavior. In contrast, the static competitive benchmark analysis model assumes that units do not operate if markups are negative and operate at capacity when price exceeds marginal costs. This static model is depicted with the light gray line. This figure suggests that intertemporal constraints do matter in firms' production decisions. By failing to account for these constraints, the static model is a poor predictor, on average, of actual production.

The intertemporal model also is a better predictor of when power plants start up. Pre-restructuring, the average number of times a unit in my sample started each month was 5.09. ${ }^{29}$ Over this period, the intertemporal model predicts 4.78 starts per month, while the static model predicts approximately twice as many (11.76 per month). To address the implied start-up costs of these models, I use a revealed preferences argument. If a firm opts to shut down and restart a unit, it must be the case that the unit's start-up costs are no larger than the profits earned (in expectation) when running. Using the predicted and actual output decisions for the $N$ units in my sample over the $T$ hours of the pre-restructuring period, I calculate the average producer surplus per start:

$$
\frac{\sum_{i=1}^{N} \sum_{t=1}^{T}\left(P_{t}-c_{i t}\right) \cdot\left(x_{i t}+S_{i t}\right)}{\sum_{i=1}^{N} \sum_{t=1}^{T} f\left(x_{i t}+S_{i t}\right)},
$$

using the notation from equations (3) and (4). The average surplus is an upper bound on the implied start-up costs. For

I define the number of equally spaced points to be 30 and use an Epanechnikov weight function.

${ }^{29} \mathrm{~A}$ start is defined as zero production in the previous hour and production of at least one MWh both in the current hour and in the following hour. the units in my sample, an engineering model (Kahn, 2000) assumes an (unweighted) average start-up cost of $\$ 1,821$. For the pre-restructured period, the average surplus per start is $\$ 1,666$ using actual production data; $\$ 1,740$ using the intertemporal model; and $\$ 820$ using the static model. The actual average surplus is double that of the static model, while the intertemporal model is a close proxy.

\section{B. Comparing Output Predictions by Fuel Type}

Another interesting comparison examines which types of power plants operate under these alternative models. Coal units, which are primarily used for baseload and "shoulder" hour production, typically have larger start-up costs than oil and natural gas fired units. Seeing differences in types of generating units could provide further evidence of the importance of intertemporal constraints. Furthermore, from an environmental perspective, there may be significant consequences as to whether coal, oil, or natural gas plants are operating.

By fuel type, I compare actual production with the production estimates of both models for the pre-restructuring period. In aggregate, production levels are similar. ${ }^{30}$ By fuel type, the intertemporal model predicts output levels similar to actual production levels: coal $(-0.1 \%)$ is used slightly less, while oil (2.5\%) and natural gas (2.7\%) are used slightly more. In contrast, the static model overstates the use of coal $(9.4 \%)$, and vastly understates the use of oil $(-46.1 \%)$ and natural gas $(-64.2 \%) .^{31}$

\section{Measuring Aggregate Welfare Effects}

Intertemporal constraints may substantially affect output decisions and lead the static model to overestimate welfare loss. Here, I measure welfare loss based on direct production costs, namely the variable costs excluding start-up costs. During peak hours, intertemporal constraints will lead to units with moderate marginal cost of production not starting. This will require units with high marginal costs of production to operate, increasing the direct production costs. In contrast, during the middle of the night, intertemporal constraints will lead to moderate cost units operating at a loss but avoiding start-up costs the next morning.

In measuring price-cost margins, $\mathrm{BBW}$ argue that these intertemporal biases are potentially offsetting. Some hours intertemporal constraints increase marginal costs, while in other hours these constraints decrease the costs. However, in the case of measuring welfare, the static model will always overstate welfare losses in competitive markets. If firms

${ }^{30}$ This is not surprising given the methods used to estimate the intertemporal model and to construct the static model.

${ }^{31}$ For both models, coal is used even more after restructuring, while oil and gas are used even less. See Mansur (forthcoming) for an analysis of the environmental consequences of firms' exercising market power in the PJM market after restructuring. 
Table 3.-Welfare Implications of Production Inefficiencies, Pre- and Post-Restructuring Using Actual Prices

\begin{tabular}{|c|c|c|c|c|}
\hline Type & Pre- & Post- & Change & Percentage \\
\hline \multicolumn{5}{|l|}{ Actual Outcomes } \\
\hline Output & 71.8 & 67.7 & -4.1 & $-6 \%$ \\
\hline Average variable costs & 18.46 & 22.15 & 3.70 & $20 \%$ \\
\hline Total variable costs & 1,325 & 1,499 & 173.4 & $13 \%$ \\
\hline \multicolumn{5}{|l|}{ Static Model } \\
\hline Output & 71.8 & 67.7 & -4.1 & $-6 \%$ \\
\hline Average variable costs & 16.82 & 19.60 & 2.78 & $17 \%$ \\
\hline Total variable costs & 1,207 & 1,326 & 118.5 & $10 \%$ \\
\hline Deadweight loss & 117.8 & 172.8 & 54.9 & $47 \%$ \\
\hline DWL share of comp. costs & $(9.8 \%)$ & $(13.0 \%)$ & & \\
\hline \multicolumn{5}{|l|}{ Intertemporal Model } \\
\hline Output & 72.0 & 67.7 & -4.3 & $-6 \%$ \\
\hline Average variable costs & 18.49 & 21.50 & 3.01 & $16 \%$ \\
\hline Total variable costs & 1,331 & 1,456 & 124.9 & $9 \%$ \\
\hline Deadweight loss & -6.0 & 42.6 & 48.6 & \\
\hline (Standard errors) & $(0.2)$ & $(11.2)$ & $(11.2)$ & \\
\hline DWL share of comp. costs & $(-0.4 \%)$ & $(2.9 \%)$ & & \\
\hline DWL ratio (intertemp./static) & $-5 \%$ & $25 \%$ & & \\
\hline
\end{tabular}

deviate from the static model's least-cost dispatch in any way, then variable production costs will necessarily increase.

In this market, short-run welfare loss only results from production inefficiencies. I compare the total variable costs of actual production $\left(q_{i t}\right)$ with the total variable costs of the competitive counterfactual estimates using both the static $\left(\hat{q}_{i t}^{*}\right)$ and intertemporal $\left(\hat{q}_{i t}\right)$ models. As in section III, I assume variable costs to be a linear function: $c_{i t} q_{i t}$. For a sample of $T$ hours and $N$ units in PJM, I measure the welfare effects $\left(\Delta W^{*}, \Delta \hat{W}\right)$ to be

$$
\begin{aligned}
& \Delta W^{*}=\sum_{t=1 i=1}^{T} \sum_{i t}^{N} c_{i t} \cdot\left(q_{i t}-q_{i t}^{*}\right), \text { and } \\
& \Delta \hat{W}=\sum_{t=1 i=1}^{T} \sum_{i t}^{N} c_{i t} \cdot\left(q_{i t}-\hat{q}_{i t}\right) .
\end{aligned}
$$

Note that this measure of welfare does not directly account for any changes in start-up costs or other intertemporal constraints.

In order to place bounds on the amount of deadweight loss associated with exercising market power in this restructured electricity market, I estimate welfare loss using both actual prices and counterfactual competitive price estimates. Actual prices exceeding those of a competitive equilibrium result in too much production and therefore higher production costs, placing a lower bound on the welfare loss. Conservative estimates of competitive prices result in low prices, resulting in too little production. This places an upper bound on the welfare loss estimate.

\section{A. Welfare Effects Given Actual Prices}

First, I measure lower bounds of the welfare estimates using actual prices. Table 3 examines both the welfare implications of restructuring and the importance of intertemporal constraints in measuring these welfare effects. The generating units in my sample actually produced 72 million MWh in the summer of 1998 and 68 million MWh in the following summer. In 1998, the actual production costs totaled $\$ 1.33$ billion. In 1999, these costs increased by $13 \%$ to $\$ 1.50$ billion. These costs are compared with those of both the static and intertemporal models.

The predictions of $q_{i t}^{*}$ that are based on the static competitive benchmark analysis method imply substantial welfare loss from restructuring. In the summer of 1999, the static model's predicted costs equaled $\$ 1.33$ billion, implying that production inefficiencies $\left(\Delta W^{*}\right)$ totaled $\$ 173$ million. Welfare losses were $13 \%$ of the competitive production cost estimates. However, this method also predicts losses even before restructuring. For 1998, this static model's predictions of variable production costs were only $\$ 1.21$ billion. This is $\$ 118$ million, or $10 \%$, less than actual production costs. This model is simulated and therefore, conditional its assumptions, there are no standard errors for these calculations.

One way to account for intertemporal constraints is to treat the pre-restructuring static model estimates as a control group. Assuming that the welfare loss estimates in 1998 resulted solely from the bias of ignoring these constraints, the welfare effects from restructuring-related market imperfections equal the change in total welfare losses from 1998 to 1999 , or $\$ 55$ million. Note that this calculation provides an accurate measure of the welfare effects only if the bias is constant over time. However, in most cases, demand and cost shocks will impact this bias. Furthermore, this method requires a control period when prices are assumed to be determined competitively.

The second method of predicting competitive production, $\hat{q}_{i t}$, is based on the intertemporal model. Recall that this reduced-form method does not impose an equilibrium constraint. Nevertheless, the predicted output is similar to actual output given the observed price-cost markups. 
Table 4.-Welfare Implications with Predicted Prices, Pre- and Post-Restructuring Using Counterfactual Competitive Price Estimates

\begin{tabular}{|c|c|c|c|c|}
\hline Type & Pre- & Post- & Change & Percentage \\
\hline \multicolumn{5}{|l|}{ Wholesale Prices } \\
\hline Actual & 26.05 & 37.97 & 11.93 & $46 \%$ \\
\hline (standard deviation) & $(43.47)$ & $(101.00)$ & $(57.53)$ & $132 \%$ \\
\hline Estimated & 26.05 & 31.53 & 5.48 & $21 \%$ \\
\hline (standard deviation) & $(43.47)$ & $(56.98)$ & $(13.51)$ & $31 \%$ \\
\hline \multicolumn{5}{|l|}{ Actual Outcomes } \\
\hline Output & 71.8 & 67.7 & -4.1 & $-6 \%$ \\
\hline Average variable costs & 18.46 & 22.15 & 3.70 & $20 \%$ \\
\hline Total variable costs & 1,325 & 1,499 & 173.4 & $13 \%$ \\
\hline \multicolumn{5}{|l|}{ Static Model } \\
\hline Output & 72.0 & 65.4 & -6.6 & $-9 \%$ \\
\hline Average variable costs & 16.60 & 19.01 & 2.42 & $15 \%$ \\
\hline Total variable costs & 1,195 & 1,243 & 48.8 & $4 \%$ \\
\hline Deadweight loss & 130.6 & 255.2 & 124.6 & $95 \%$ \\
\hline DWL share of comp. costs & $(10.9 \%)$ & $(20.5 \%)$ & & \\
\hline \multicolumn{5}{|l|}{ Intertemporal Model } \\
\hline Output & 72.0 & 65.4 & -6.6 & $-9 \%$ \\
\hline Average variable costs & 18.49 & 21.31 & 2.82 & $15 \%$ \\
\hline Total variable costs ( $\$$ millions $)$ & 1,331 & 1,394 & 62.6 & $5 \%$ \\
\hline Deadweight loss & -6.0 & 104.8 & 110.8 & \\
\hline DWL share of comp. costs & $(-0.4 \%)$ & $(7.5 \%)$ & & \\
\hline DWL ratio (intertemp./static) & $-5 \%$ & $41 \%$ & & \\
\hline
\end{tabular}

Notes: Prices are in dollars per MWh. Output is reported in millions of MWh. Average variable costs are in $\$$ MWh. Total variable costs and deadweight loss are reported in millions of dollars.

In the summer of 1998, the intertemporal model's total variable cost estimates equaled $\$ 1.33$ billion, just $\$ 6$ million above actual costs. Note that this is not surprising given that the coefficients are estimated using these pre-restructuring data. However, in 1999, the intertemporal production estimates were $\$ 1.46$ billion. These cost differences imply production inefficiencies $(\Delta) \widehat{W}$ ) of $\$ 43$ million, or $3 \%$, after restructuring. I compute standard errors on this welfare loss measure based on the errors from section VI. ${ }^{32}$ The standard error on the production inefficiencies in 1999 is $\$ 11$ million. In each year, the intertemporal model predicts less welfare loss than the static model.

Relative to wealth transfers, the intertemporal model's estimates of deadweight loss are small. Mansur (2007) estimates that the costs of procuring electricity from the PJM spot market during the summer of 1999 exceeded the estimated procurement costs of a perfectly competitive market by $\$ 182$ million. The spot market accounts for only $10 \%$ to $15 \%$ of all sales. An additional $30 \%$ of electricity is sold through bilateral contracts. ${ }^{33}$ If these contracts reflect markups similar to those in the spot market, then the total procurement costs increase by $\$ 676$ million.

I assert that firms behaved competitively before restructuring in 1998. Therefore, I attribute most of the welfare

\footnotetext{
${ }^{32}$ First, I compute the errors on the predicted output for each unit and hour. I multiply these standard errors by the marginal cost of production and square the product. This is the measure of variance for the variable costs of each unit and hour. Finally, I sum across these variances for all units and hours in a summer. The square root of this sum equals the standard error of the total variable costs. For 1998, the standard errors are 0.2 million.

${ }^{33}$ In a personal communication, Joe Bowring of the Market Monitoring Unit estimated this level of contracts. In addition, $10 \%$ to $15 \%$ of supply comes from spot market purchases, $1 \%$ to $2 \%$ from imports, and the remaining $53 \%$ to $59 \%$ is self-supplied by firms.
}

loss that the static model predicts for 1998 to be actual production costs that result from intertemporal constraints. Of these $\$ 118$ million in variable costs, at most $17 \%$ can be attributed to start-up costs. As noted by BBW, an upper bound on the share of these variable costs that may be attributed to start-up costs is the amount that firms actually spent starting up. The sampled units' actual number of starts fell from 4,213 (in the summer of 1998) to 4,081 (in the summer of 1999). Using data on start-up costs from Kahn (2000), the cost of these observed starts totaled \$21.6 million in 1998 and \$20.4 million in 1999. These findings suggest that other intertemporal constraints, like ramping rates and minimum run times, also affect firms' production decisions.

\section{B. Welfare Effects Given Competitive Prices}

If firms did set high prices, then a competitive counterfactual requires price estimates from a competitive model. Furthermore, the higher observed prices will result in greater predicted production post-restructuring than would have occurred under competitive prices. Appendix A describes how I construct counterfactual competitive prices that are likely to provide an upper bound on these costs.

Table 4 exhibits the welfare results using these predicted prices. The predicted prices after restructuring average $\$ 32 /$ MWh in contrast to the $\$ 38 / \mathrm{MWh}$ average of observed prices. These lower prices resulted in less production by all firms. The predicted output totals 65.4 million MWh over the summer of 1999, 2.3 million less than observed. This reduction in output means that firms incurred fewer variable costs. These costs total only $\$ 1,394$ million using the intertemporal model, or $\$ 105$ million below the actual costs. 
Table 5.-Output Production and Welfare Implications by Firm and Model, Pre- vs. Post-Restructuring, Using Actual Prices

\begin{tabular}{|c|c|c|c|c|c|c|c|c|}
\hline \multicolumn{9}{|c|}{ Panel A: Actual Outcomes } \\
\hline \multirow[b]{2}{*}{ Firm } & \multicolumn{4}{|c|}{ Output } & \multicolumn{4}{|c|}{ Total Variable Costs } \\
\hline & Pre- & Post- & Change & Percentage & Pre- & Post- & Change & Percentage \\
\hline Public Service & 3,791 & 4,213 & 422 & $11 \%$ & 95 & 137 & 42.8 & $45 \%$ \\
\hline PECO & 3,047 & 2,728 & -319 & $-10 \%$ & 66 & 73 & 6.9 & $10 \%$ \\
\hline GPU, Inc. & 19,208 & 18,106 & $-1,102$ & $-6 \%$ & 295 & 349 & 54.7 & $19 \%$ \\
\hline PPL, Inc. & 13,344 & 10,752 & $-2,592$ & $-19 \%$ & 258 & 244 & -14.3 & $-6 \%$ \\
\hline Potomac & 11,633 & 12,183 & 550 & $5 \%$ & 244 & 287 & 43.0 & $18 \%$ \\
\hline Baltimore & 8,772 & 8,700 & -72 & $-1 \%$ & 157 & 158 & 1.8 & $1 \%$ \\
\hline Delmarva & 3,522 & 3,129 & -393 & $-11 \%$ & 77 & 87 & 9.8 & $13 \%$ \\
\hline Atlantic City & 1,152 & 1,235 & 83 & $7 \%$ & 29 & 41 & 12.1 & $42 \%$ \\
\hline Other & 7,320 & 6,613 & -707 & $-10 \%$ & 106 & 122 & 16.7 & $16 \%$ \\
\hline Total & 71,789 & 67,659 & $-4,130$ & $-6 \%$ & 1,325 & 1,499 & 173.4 & $13 \%$ \\
\hline \multicolumn{9}{|c|}{ Panel B: Intertemporal Model Estimates } \\
\hline & \multicolumn{4}{|c|}{ Output } & \multicolumn{4}{|c|}{ Total Variable Costs } \\
\hline Firm & Pre- & Post- & Change & Percentage & Pre- & Post- & Change & Percentage \\
\hline Public Service & 3,828 & 3,259 & -569 & $-15 \%$ & 96 & 104 & 8.7 & $9 \%$ \\
\hline PECO & 3,096 & 2,883 & -213 & $-7 \%$ & 67 & 74 & 6.8 & $10 \%$ \\
\hline GPU, Inc. & 19,213 & 18,033 & $-1,180$ & $-6 \%$ & 295 & 346 & 50.9 & $17 \%$ \\
\hline PPL, Inc. & 13,362 & 12,373 & -989 & $-7 \%$ & 259 & 280 & 20.9 & $8 \%$ \\
\hline Potomac & 11,701 & 11,331 & -370 & $-3 \%$ & 246 & 254 & 8.2 & $3 \%$ \\
\hline Baltimore & 8,780 & 8,785 & 5 & $0 \%$ & 157 & 158 & 0.9 & $1 \%$ \\
\hline Delmarva & 3,529 & 3,131 & -398 & $-11 \%$ & 77 & 81 & 4.5 & $6 \%$ \\
\hline Atlantic City & 1,160 & 1,053 & -107 & $-9 \%$ & 29 & 35 & 5.6 & $19 \%$ \\
\hline Other & 7,319 & 6,811 & -508 & $-7 \%$ & 106 & 124 & 18.2 & $17 \%$ \\
\hline Total & 71,988 & 67,659 & $-4,329$ & $-6 \%$ & 1,331 & 1,456 & 124.7 & $9 \%$ \\
\hline \multicolumn{9}{|c|}{ Panel C: Static Model Estimates } \\
\hline & \multicolumn{4}{|c|}{ Output } & \multicolumn{4}{|c|}{ Total Variable Costs } \\
\hline Firm & Pre- & Post- & Change & Percentage & Pre- & Post- & Change & Percentage \\
\hline Public Service & 2,650 & 2,030 & -620 & $-23 \%$ & 56 & 58 & 2.0 & $4 \%$ \\
\hline PECO & 3,653 & 2,699 & -954 & $-26 \%$ & 74 & 61 & -12.9 & $-17 \%$ \\
\hline GPU, Inc. & 20,431 & 18,813 & $-1,618$ & $-8 \%$ & 301 & 349 & 47.9 & $16 \%$ \\
\hline PPL, Inc. & 13,697 & 11,679 & $-2,018$ & $-15 \%$ & 238 & 245 & 7.0 & $3 \%$ \\
\hline Potomac & 10,444 & 11,874 & 1,430 & $14 \%$ & 197 & 233 & 36.4 & $18 \%$ \\
\hline Baltimore & 8,931 & 9,457 & 526 & $6 \%$ & 148 & 160 & 12.2 & $8 \%$ \\
\hline Delmarva & 3,076 & 2,497 & -579 & $-19 \%$ & 62 & 61 & -1.0 & $-2 \%$ \\
\hline Atlantic City & 657 & 411 & -246 & $-37 \%$ & 16 & 13 & -2.6 & $-16 \%$ \\
\hline Other & 8,245 & 8,198 & -47 & $-1 \%$ & 116 & 145 & 29.4 & $25 \%$ \\
\hline Total & 71,784 & 67,658 & $-4,126$ & $-6 \%$ & 1,207 & 1,326 & 118.5 & $10 \%$ \\
\hline
\end{tabular}

Notes: Output is measured in GWh's (1,000s of MWh) and total variable costs are measured in millions of dollars.

This is $7.5 \%$ of the predicted costs, more than double the estimates in section VIIA.

Note that the 2.3 million MWh output shortfall must be produced somehow. In other words, the excess demand implies that the competitive prices, in equilibrium, must be greater than these predicted ones. Therefore, the $\$ 105$ million provides an upper bound on the welfare loss.

Similarly, the static model shows increases in welfare losses. For comparison purposes, I solved the static model such that the aggregate amount produced equals the amount produced in the intertemporal model (versus actual production). The total variable costs of $\$ 1,243$ million in 1999 are $\$ 256$ million less than the observed costs. The same caveat as with the intertemporal model applies here. That said, the upper bound of welfare losses using the static model is $21 \%$ of estimated costs after restructuring.
I conclude that the welfare losses are greater with the predicted prices than with actual prices. However, the intertemporal model's losses are still $\$ 100$ million less than those of the static model. In other words, the static model continues to exhibit substantial biases. I find qualitatively similar results using several other measures of price. ${ }^{34}$

\section{Response of Nonmodeled Firms}

Next, I examine how other firms that are not directly modeled would change behavior given the alternative pre-

\footnotetext{
34 These alternative prices include the $\bar{p}_{t}$ price estimates described in appendix A without the additional error terms, the price estimates multiplied by a mean-preserving variable that increases the variance by a uniform amount, price estimates from a GARCH model, and competitive price estimates based on the static model from Mansur (2007).
} 
dicted prices from section VII B. If actual prices exceed those of a competitive market, then not only would the modeled firms have produced less in a competitive regime, but so would those power plants that are not directly modeled, including imports. Appendix B discusses how I estimate the supply function and variable costs for these nonmodeled firms.

Both pre- and post-restructuring, the nonmodeled firms are more price sensitive during peak hours. The implied average elasticities pre-restructuring are 0.19 , during peak hours, and 0.13 off-peak (and only weakly significant). Post-restructuring, the elasticities are even smaller: 0.08 on peak and 0.06 off-peak (and insignificant).

The actual output of these firms increased by 7.7 million MWh from the summer of 1998 to the summer of 1999. However, even with the predicted prices, the firms increase output by 7.2 million MWh. In other words, with inelastic supply from these nonmodeled firms, there is not much difference in their production decisions even when the predicted prices are substantially lower than the actual ones.

Given the modest response by these firms, the additional welfare effect is only $\$ 32$ million. Note that these welfare effects are the same for both the intertemporal and the static model. With a more complex intertemporal model that estimates equilibrium competitive prices, one could compare that approach's prices with the static model's prices. However, as BBW note, intertemporal constraints both bias their price simulations upwards and downwards in different situations. Therefore, it is not clear for which model the welfare loss would be greater given my nonmodeled firms' supply function.

\section{Firm-Level Analysis}

Next, I examine whether these welfare effects are consistent with the incentives of firms. Table 5 compares the actual and estimated production and welfare loss of each of the major firms in PJM before and after restructuring. From 1998 to 1999, PECO and PPL reduced actual output at their units in my sample by $10 \%$ and $19 \%$, respectively. The intertemporal model also predicts a reduction in output, but only of $7 \%$ for each firm.

The observed output for most of the other firms was similar to that predicted by the intertemporal model. However, PSE\&G did increase production substantially. Rather than reduce output by $15 \%$ as my model predicts, it increased production by $11 \%$ from the summer of 1998 to the summer of 1999. As discussed in section IIB, this is also consistent with the firm's incentives.

For the oligopolists, PECO and PPL, figure 4 shows the goodness-of-fit comparison of utilization rates across pricecost markups. I smooth the data using the same kernel regression method as the previous figure. Unlike figure 3, this figure shows the relationship for both the pre- and post-restructuring summers. In the pre-restructuring period,
Figure 4.-Fit Comparison of Utilization Rates across Price-Cost Markup for Strategic Firms (PECO AND PPL), Pre-Restructuring (Summer 1998) ANd Post-Restructuring (Summer 1999)

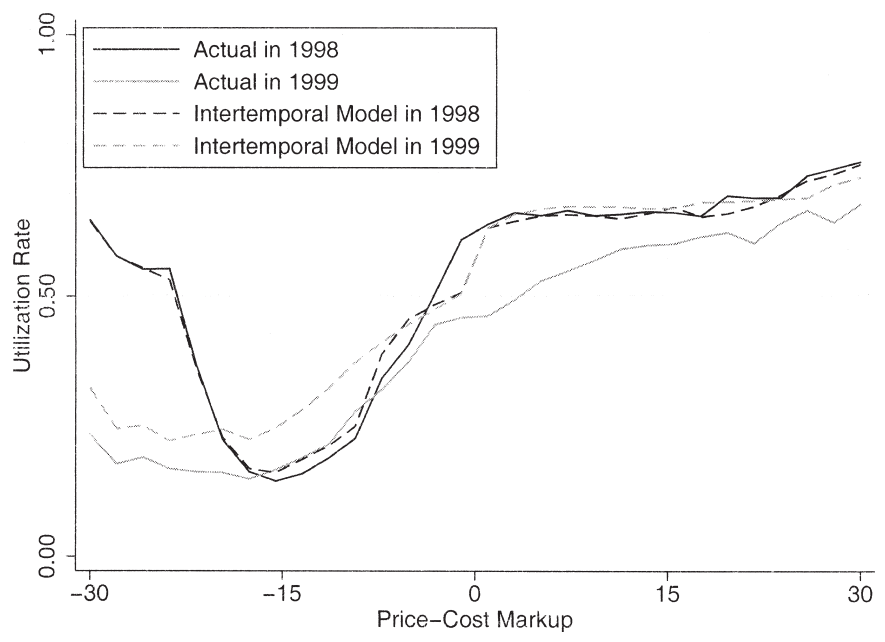

the intertemporal model "supply" function is similar to the observed. However, after restructuring, these firms produced less than predicted for a given markup.

In the bottom panel of table 5, note that the static model predicts much larger reductions for some firms. For example, based on the static model's estimates post-restructuring, one might conclude that GPU and Baltimore Gas \& Electric, as well as PPL, produced less than would be expected given the observed prices. For either the static or intertemporal model, PSE\&G produced more after restructuring than predicted.

Table 5 also reports the welfare effects of these production distortions. As with production, PSE\&G's variable costs were much greater in 1999 than predicted. In contrast, PPL's costs were substantially lower. Overall, the oligopolists' actual production costs were $\$ 37$ million less than those predicted by the intertemporal model. In contrast, actual production costs were $\$ 79$ million greater for the other firms.

These firm-level effects are relatively robust to the counterfactual competitive price estimates. Table 6 reports the firm-level output and welfare effects for the intertemporal and static models using the predicted prices. The comparison with actual behavior is more difficult to make as aggregate production is less than the observed with these predicted prices. Nevertheless, PPL produced less than even that suggested by the intertemporal model using these counterfactual prices. With these prices, the oligopolists' actual production costs were $\$ 17$ million less than those predicted by the intertemporal model, while they were $\$ 121$ million greater for the other firms.

\section{Conclusions}

The competitive benchmark analysis method for measuring competition in restructured wholesale electricity markets has 
Table 6.-Output Production and Welfare Implications by Firm and Model, Pre- vs. Post-Restructuring, Using Counterfactual Competitive PRICE ESTIMATES

\begin{tabular}{|c|c|c|c|c|c|c|c|c|}
\hline \multicolumn{9}{|c|}{ Panel A: Actual Outcomes } \\
\hline \multirow[b]{2}{*}{ Firm } & \multicolumn{4}{|c|}{ Output } & \multicolumn{4}{|c|}{ Total Variable Costs } \\
\hline & Pre- & Post- & Change & Percentage & Pre- & Post- & Change & Percentage \\
\hline Public Service & 3,791 & 4,213 & 422 & $11 \%$ & 95 & 137 & 42.8 & $45 \%$ \\
\hline PECO & 3,047 & 2,728 & -319 & $-10 \%$ & 66 & 73 & 6.9 & $10 \%$ \\
\hline GPU, Inc. & 19,208 & 18,106 & $-1,102$ & $-6 \%$ & 295 & 349 & 54.7 & $19 \%$ \\
\hline PPL, Inc. & 13,344 & 10,752 & $-2,592$ & $-19 \%$ & 258 & 244 & -14.3 & $-6 \%$ \\
\hline Potomac & 11,633 & 12,183 & 550 & $5 \%$ & 244 & 287 & 43.0 & $18 \%$ \\
\hline Baltimore & 8,772 & 8,700 & -72 & $-1 \%$ & 157 & 158 & 1.8 & $1 \%$ \\
\hline Delmarva & 3,522 & 3,129 & -393 & $-11 \%$ & 77 & 87 & 9.8 & $13 \%$ \\
\hline Atlantic City & 1,152 & 1,235 & 83 & $7 \%$ & 29 & 41 & 12.1 & $42 \%$ \\
\hline Other & 7,320 & 6,613 & -707 & $-10 \%$ & 106 & 122 & 16.7 & $16 \%$ \\
\hline Total & 71,789 & 67,659 & $-4,130$ & $-6 \%$ & 1,325 & 1,499 & 173.4 & $13 \%$ \\
\hline \multicolumn{9}{|c|}{ Panel B: Intertemporal Model Estimates } \\
\hline & \multicolumn{4}{|c|}{ Output } & \multicolumn{4}{|c|}{ Total Variable Costs } \\
\hline Firm & Pre- & Post- & Change & Percentage & Pre- & Post- & Change & Percentage \\
\hline Public Service & 3,828 & 2,611 & $-1,217$ & $-32 \%$ & 96 & 87 & -9.1 & $-9 \%$ \\
\hline PECO & 3,096 & 2,436 & -660 & $-21 \%$ & 67 & 63 & -4.1 & $-6 \%$ \\
\hline GPU, Inc. & 19,213 & 18,370 & -843 & $-4 \%$ & 295 & 353 & 57.6 & $20 \%$ \\
\hline PPL, Inc. & 13,362 & 11,992 & $-1,370$ & $-10 \%$ & 259 & 271 & 11.9 & $5 \%$ \\
\hline Potomac & 11,701 & 11,126 & -575 & $-5 \%$ & 246 & 245 & -0.9 & $0 \%$ \\
\hline Baltimore & 8,780 & 8,214 & -566 & $-6 \%$ & 157 & 146 & -11.2 & $-7 \%$ \\
\hline Delmarva & 3,529 & 2,710 & -819 & $-23 \%$ & 77 & 71 & -5.4 & $-7 \%$ \\
\hline Atlantic City & 1,160 & 965 & -195 & $-17 \%$ & 29 & 32 & 3.3 & $11 \%$ \\
\hline Other & 7,319 & 6,984 & -335 & $-5 \%$ & 106 & 126 & 20.6 & $19 \%$ \\
\hline Total & 71,988 & 65,408 & $-6,580$ & $-9 \%$ & 1,331 & 1,394 & 62.6 & $5 \%$ \\
\hline \multicolumn{9}{|c|}{ Panel C: Static Model Estimates } \\
\hline & \multicolumn{4}{|c|}{ Output } & \multicolumn{4}{|c|}{ Total Variable Costs } \\
\hline Firm & Pre- & Post- & Change & Percentage & Pre- & Post- & Change & Percentage \\
\hline Public Service & 2,650 & 1,389 & $-1,261$ & $-48 \%$ & 56 & 39 & -16.8 & $-30 \%$ \\
\hline PECO & 3,653 & 2,531 & $-1,122$ & $-31 \%$ & 74 & 54 & -19.8 & $-27 \%$ \\
\hline GPU, Inc. & 20,431 & 19,081 & $-1,350$ & $-7 \%$ & 301 & 352 & 50.9 & $17 \%$ \\
\hline PPL, Inc. & 13,697 & 11,154 & $-2,543$ & $-19 \%$ & 238 & 227 & -11.0 & $-5 \%$ \\
\hline Potomac & 10,444 & 11,393 & 949 & $9 \%$ & 197 & 213 & 16.5 & $8 \%$ \\
\hline Baltimore & 8,931 & 9,380 & 449 & $5 \%$ & 148 & 156 & 8.1 & $5 \%$ \\
\hline Delmarva & 3,076 & 2,026 & $-1,050$ & $-34 \%$ & 62 & 48 & -13.7 & $-22 \%$ \\
\hline Atlantic City & 657 & 252 & -405 & $-62 \%$ & 16 & 8 & -7.9 & $-49 \%$ \\
\hline Other & 8,245 & 8,196 & -49 & $-1 \%$ & 116 & 145 & 29.1 & $25 \%$ \\
\hline Total & 71,784 & 65,402 & $-6,382$ & $-9 \%$ & 1,207 & 1,243 & 36.3 & $3 \%$ \\
\hline
\end{tabular}

identified market failures in many markets. This static method ignores intertemporal constraints such as the cost of starting a power plant. This may result in competitive price simulations that are biased upwards in some hours and downwards in others. While the measurement error of this simplification may be partially offsetting in measuring price, it will overstate actual welfare loss due to changes in production costs (which ignore changes in start-up costs). In other words, if production constraints bind, then these production costs will increase. For example, I find that-even in the summer before restructuring - the actual variable costs of production were $10 \%$ above the competitive counterfactual costs. After restructuring, the welfare loss is $13 \%$ to $21 \%$ of production cost estimates.

In this paper, I develop a measure of competitive production decisions to estimate welfare while accounting for production constraints. Relative to the static competitive benchmark analysis technique, my model predicts production behavior more accurately prior to restructuring. Given that firms have exercised market power, I develop a counterfactual set of prices that are consistent with competitive behavior. Comparing actual production costs with these competitive production cost estimates for the summer after restructuring, I estimate that actual costs exceeded competitive estimates by only $3 \%$ to $8 \%$, substantially less than the estimates using the static technique.

The paper also examines whether these welfare effects are consistent with firms' incentives. Two PJM firms had incentives to increase prices in the summer of 1999. I find that these strategic firms did produce less, while the other pricetaking firms produced more. The welfare effects are 
similarly distributed. Namely, for the oligopolists, actual production costs were about $5 \%$ to $10 \%$ less than those predicted by the intertemporal model. In contrast, actual production costs were $7 \%$ to $11 \%$ greater for the pricetaking firms. For these reasons, the welfare losses measured in this paper are likely the result of firms' exercising market power.

In conclusion, I find that intertemporal constraints result in significant non-convexities in the costs of producing electricity. This suggests that one should be cautious using measures of welfare effects that ignore the firms' dynamic optimization problem. Finally, further research on modeling strategic firms' dynamic problem in these restructured markets may provide insight into firm behavior and help develop better restructured markets.

\section{REFERENCES}

Borenstein, Severin, James B. Bushnell, and Frank A. Wolak, "Measuring Market Inefficiencies in California's Restructured Wholesale Electricity Market," American Economic Review 92:5 (2002), 13761405 .

Borenstein, Severin, and Joseph Farrell, "Is Cost Cutting Evidence of X-Inefficiency?" American Economic Review 90:2 (2000), 224 227.

Bushnell, James B., Erin T. Mansur, and Celeste Saravia, "Vertical Arrangements, Market Structure, and Competition: An Analysis of Restructured U.S. Electricity Markets," American Economic Review (forthcoming).

Bushnell, James B., and Celeste Saravia, "An Empirical Assessment of the Competitiveness of the New England Electricity Market," CSEM working paper no. 101 (2002).

Davidson, Russell, and James G. MacKinnon, Estimation and Inference in Econometrics (New York: Oxford University Press, 1993).

Fabra, Natalia, and Juan Toro, "Price Wars and Collusion in the Spanish Electricity Market," International Journal of Industrial Organization 23:3-4 (2005), 155-181.

Harvey, Scott M., and William W. Hogan, "On the Exercise of Market Power through Strategic Withholding in California," Kennedy School of Government working paper (2001a).

"Identifying the Exercise of Market Power in California," Kennedy School of Government working paper (2001b).

Holland, Stephen P., and Erin T. Mansur, "Is Real-Time Pricing Green?: The Environmental Impacts of Electricity Demand Variance," this REVIEW (forthcoming).

Hortaçsu, Ali, and Steven L. Puller, "Testing Strategic Models of Firm Behavior in Restructured Electricity Markets: A Case Study of ERCOT," RAND Journal of Economics (forthcoming).

Joskow, Paul L., and Edward Kahn, "A Quantitative Analysis of Pricing Behavior in California's Wholesale Electricity Market during Summer 2000," Energy Journal 23:4 (2002), 1-35.

Kahn, Edward, Workpapers in Public Utilities Commission of Ohio, case no. 99-EL-ETP (2000)

Levin, Dan, "Taxation within Cournot Oligopoly," Journal of Public Economics 27:3 (1985), 281-290.

Mansur, Erin T., "Upstream Competition and Vertical Integration in Electricity Markets," Journal of Law and Economics 50:1 (2007). "Do Oligopolists Pollute Less? Evidence from a Restructured Electricity Market," Journal of Industrial Economics (forthcoming).

Market Monitoring Unit, PJM Interconnection State of the Market Report, 1999 (2000).

Murphy, Kevin M., and Robert H. Topel, "Estimation and Inference in Two-Step Econometric Models," Journal of Business \& Economic Statistics 3:4 (1985), 88-97.

Newey, Whitney K., and West, Kenneth D., "A Simple Positive Definite, Heteroskedasticity and Autocorrelation Consistent Covariance Matrix," Econometrica 55 (1987), 703-705.
Puller, Steven L., "Pricing and Firm Conduct in California's Deregulated Electricity Market," this REVIEW 89:1 (2007), 75-87.

Schweppe, Fred C., Michael C. Caramanis, Richard E. Tabors, and Roger E. Bohn, Spot Pricing of Electricity (Norwell, MA: Kluwer Academic Publishers, 1988)

Sheble, G. B., and G. N. Fahd, "Unit Commitment Literature Synopsis," IEEE Transactions on Power Systems 9:1 (1994), 128-135.

Smith, Rebecca, and John J. Fialka, "Electricity Firms Play Many Power Games that Jolt Consumers," The Wall Street Journal (August 4, 1999), page A1.

Wolak, Frank A., "An Empirical Analysis of the Impact of Hedge Contracts on Bidding Behavior in a Competitive Electricity Market," International Economic Journal 14:2 (2000), 1-39. "Measuring Unilateral Market Power in Wholesale Electricity Markets: The California Market, 1998-2000," American Economic Review 93:2 (2003), 425-430.

Wolfram, Catherine D., "Strategic Bidding in a Multiunit Auction: An Empirical Analysis of Bids to Supply Electricity in England and Wales," RAND Journal of Economics 29:4 (1998), 703-725.

"Measuring Duopoly Power in the British Electricity Spot Market," American Economic Review 89:4 (1999), 805-826.

\section{APPENDIX A}

\section{Predicted Prices}

This appendix discusses how I predict prices that are consistent with competitive behavior. I use an approach similar to the method that I use to predict firms' supply decisions (in section IV). Namely, I examine the relationship between prices $\left(p_{t}\right)$ pre-restructuring and the quantity demanded. As in BBW, I focus on the demand for fossil supply by subtracting the inframarginal production of hydroelectric and nuclear power plants. Derived demand is perfectly inelastic and these nonfossil generators are not likely to respond substantially to wholesale prices. Thus, net demand $\left(D_{t}^{\text {net }}\right)$ is assumed to be perfectly inelastic and the quantity of net demand will not be correlated with the error term of prices. Hence, ordinary-least-squares estimates are unbiased. I allow the coefficient on net demand to vary by hour-of-day $i$ (as well as include hour-of-day fixed effects) and use a ten-part piecewise linear spline function (split by decile for each hour):

$$
p_{t}=\alpha_{i}+\sum_{j(i)=1}^{10} \beta_{i, j(i)} D_{t}^{n e t}+e_{t} .
$$

Figure A1.-Actual Prices and Fitted Values for Pre- AND POST-RESTRUCTURING

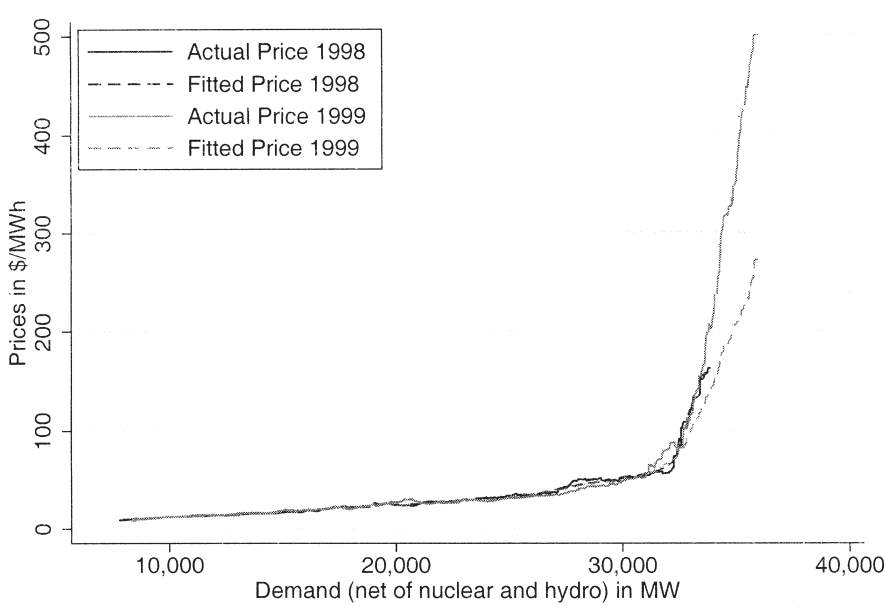

Notes: The fitted values are from a regression of price on demand (net of nuclear and hydroelectric production) pre-restructuring, allowing the coefficient on demand to vary by hour and decile using a piecewise linear function. 
The function is extremely flexible and fits the pre-restructuring data with an $R^{2}$ of 0.46 .

I use these predicted coefficients to construct a second series of prices for the post-restructuring period. As in section IV, this method requires a common support. The range of net demand in the pre-restructuring summer of 1998 was from 6,301 to 36,679 MW. The summer after restructuring was quite hot. The net demand increased and the range was 6,997 to $39,841 \mathrm{MW}$. Thus, there are some predicted prices that are out of sample.

Finally, the predicted prices are adjusted to reflect the actual variance observed in 1998. Note from figure 3 that supply (the inverse of the function shown) is highly nonlinear and, for positive price-cost markups, the function is convex. Thus, by Jensen's inequality, the supply at the expected price will exceed the expected supply, particularly in highdemand hours. In 1998, the variation of the unadjusted predicted prices $\left(\bar{p}_{t}\right)$ is much lower than the variation of actual prices (29.5 and 43.5, respectively).

In order to increase the variance, I use the residuals from the regression (A1) based on the pre-restructuring data. First, I fit an AR(1) process for the residuals:

$$
\hat{e}_{t}=\rho \hat{e}_{t-1}+u_{t}
$$

and estimate $\hat{\rho}$ of 0.72 . Then I use a Monte Carlo simulation, drawing from the sample distribution of $u_{t}$ and reconstruct a new series of $\tilde{e}_{t}$, which I add to $\bar{p}_{t}$, to get the adjusted predicted prices for the post-restructuring period. This is repeated hundred times. For each set of prices, I calculate the welfare losses and report the mean. As with the main results, I use actual prices for the pre-restructuring period.

For the summers of 1998 and 1999, figure A1 shows the actual and predicted prices as a function of net demand. A kernel regression is used to smooth over the thousands of prices. The largest difference between actual and predicted prices is seen in the high-demand hours of 1999. It is these hours when firms had the greatest ability to exercise market power (Bushnell, Mansur, \& Saravia, forthcoming).

My predicted prices provide an upper bound on the welfare effects for both the intertemporal and static models. In addition to restructuring, the summer of 1999 saw an increase in input prices for natural gas, fuel oil, and sulfur dioxide. Furthermore, a new nitrogen oxides tradable permit regulation began that year, which resulted in higher costs for many power plants. The competitive pricing model focuses only on determining the average supply function and, intentionally, does not include costs. This will result in price estimates that are likely to be less than what a competitive model would have observed because the cost increases are not taken into account. Therefore, the actual prices and the predicted prices provide bounds on the size of the production costs, and therefore welfare effects, for both models.

\section{APPENDIX B}

\section{Supply Response of Nonmodeled Firms}

The quantity supplied by nonmodeled firms $\left(q_{t}^{N M}\right)$, including net imports into PJM, will depend on price. I measure $q_{t}^{N M}$ as the amount of demand not met by the firms in the sample:

$$
q_{t}^{N M}=D_{t}-\sum_{i=1}^{130} q_{i t} .
$$

Table B1.-Nonmodeled Firms Supply Function, Pre- and PostRESTRUCTURING DEPENDENT VARIABLE: HourLy NONMODELED FIRMS' QUANTITY SUPPLIED INTO PJM BY YEAR

\begin{tabular}{lcc}
\hline \hline \multicolumn{1}{c}{ Variable } & Pre- & Post- \\
\hline In(Price) $\times$ Peak & $2,851.8^{* * *}(773.3)$ & $1,372.6 * * *(525.4)$ \\
In(Price) $\times$ Off-Peak & $1,657.8^{*}(904.9)$ & $841.5(723.3)$ \\
$R$-squared & 0.08 & 0.19 \\
AR(1) coef. $(\rho)$ & 0.84 & 0.83 \\
Sample size & 4,330 & 4,341 \\
\hline
\end{tabular}

Notes: Table presents 2SLS coefficients. First I estimate 2SLS and use the errors to correct for serial correlation by estimating an $\operatorname{AR}(1)$ coefficient ( $\rho$ ). Then I quasi-difference the data by calculating $\Delta x=$ $x(t)-\rho \times x(t-1)$ for all data. I reestimate the 2SLS results using these quasi-differenced data. Robus standard errors are given in parentheses. Significance is marked with $(* * *)$ at the $1 \%$ level, $\left(*^{*}\right)$ at the $5 \%$ level, and $(*)$ at the $10 \%$ level. Regression includes month fixed effects, peak indicator (between 11 a.m. and 8 p.m. weekdays) and weather variables for bordering states (New York, Ohio, Virginia, and West Virginia), which are modeled as quadratic functions for cooling degree days (degrees daily mean below $65^{\circ} \mathrm{F}$ ) and heating degree days (degrees daily mean above $65^{\circ} \mathrm{F}$ ). In the first stage, I regress PJM In(price) on the exoting degree days (degr In(price) on the exogenous variables and instruments of daily weather for the states in PJM (Delaware, Maryland, New Jersey, and Pennsylvania) with the same flexible form as the weather for bordering states.
The sample is from April 1 to September 30 for each year: pre-restructuring (1998) and post-restructuring The sam
(1999).

To account for this price sensitivity, I use a method similar to that of Bushnell, Mansur, and Saravia (forthcoming) and Mansur (2007). For a given summer, I model net imports as a linear-log function of actual price $(P)$ in hour $t$ :

$$
\begin{aligned}
q_{t}^{N M}= & \beta_{1} \ln \left(P_{t}\right) \times \text { Peak }_{t}+\beta_{2} \ln \left(P_{t}\right) \times\left(1-\text { Peak }_{t}\right) \\
& +\sum_{m=1}^{M} \alpha_{m} \text { Month }_{m t}+\delta \text { Peak }_{t}+\sum_{s=1}^{S} \gamma_{s} \text { Temp }_{s t}+\varepsilon_{t},
\end{aligned}
$$

where Peak $k_{t}$ indicates hours between 11 a.m. and 8 p.m. on weekdays, Month $_{m t}$ is an indicator variable for each summer month, and Temp measures temperature for bordering states ${ }^{35}$ For hour $t$, the idiosyncratic error term on net imports is $\varepsilon_{t}$. The data sources and model are further described in Mansur (2007)

Prices are endogenous. I instrument using daily temperature variables in states in PJM using the same functional form as described in footnote 35. Then, I interact each instrument with both Peak ${ }_{t}$ and $\left(1-P e a k_{t}\right)$. Note that Mansur (2007) uses load as the instrument but—as I use load in my definition of $q_{t}^{N M}$ - these alternative temperature instruments are used here. Wald tests of joint significance suggest that these are strong instruments. Separately for 1998 and 1999, table B1 reports the two-stage least squares coefficient and standard error estimates for $\beta_{1}$ and $\beta_{2}$ that account for serial correlation and heteroskedasticity. ${ }^{36}$ The elasticity at the average is the coefficient divided by the average supply of nonmodeled firms. I integrate the supply function and obtain variable-cost estimates in order to measure welfare.

${ }^{35}$ The temperature variables for bordering states are modeled as quadratic functions for cooling degree days (degrees daily mean above $65^{\circ} \mathrm{F}$ ) and heating degree days (degrees daily mean below $65^{\circ} \mathrm{F}$ ). As such, $T e m p_{s t}$ has four variables for each of the four states. These data are state averages from the National Oceanic and Atmospheric Administration (NOAA) Web site's daily temperature data.

${ }^{36}$ First I estimate the IV coefficients assuming i.i.d. errors in order to calculate an unbiased estimate of $\rho$, the first-degree autocorrelation parameter. After quasi-differencing the data, I reestimate the IV coefficients while using the White technique to address heteroskedasticity. 